\title{
A NOVEL SERIES EXPANSION FOR THE MULTIVARIATE NORMAL PROBABILITY INTEGRALS BASED ON FOURIER SERIES
}

\author{
HATEM A. FAYED AND AMIR F. ATIYA
}

\begin{abstract}
In this article, we derive a series expansion of the multivariate normal probability integrals based on Fourier series. The basic idea is to transform the limits of each integral from $h_{i}$ to $\infty$ to be from $-\infty$ to $\infty$ by multiplying the integrand by a periodic square wave that approximates the domain of the integral. This square wave is expressed by its Fourier series expansion. Then a Cholesky decomposition of the covariance matrix is applied to transform the integrand to a simple one that can be easily evaluated. The resultant formula has a simple pattern that is expressed as multiple series expansion of trigonometric and exponential functions.
\end{abstract}

\section{INTRODUCTION}

A common problem that arises in many statistics computations is computing the complementary integral of the multivariate normal distribution which is given by

$$
L(h, \Sigma)=\frac{1}{\sqrt{(2 \pi)^{m}|\Sigma|}} \int_{h_{1}}^{\infty} \ldots \int_{h_{m}}^{\infty} \exp \left\{-\frac{1}{2} x^{T} \Sigma^{-1} x\right\} d x
$$

where $x=\left(x_{1}, x_{2}, \cdots, x_{m}\right)$ and $\Sigma$ is an $m \times m$ symmetric positive definite covariance matrix.

The problem has received considerable attention in the literature [14, 16, 18]. Efficient formulas exist for $m=1$ and $m=2$. For $m=2$, Pearson [21] derived the following simple tetrachoric series for the bivariate normal CDF:

$$
\Phi\left(h_{1}, h_{2}, \rho\right)=\Phi(h) \Phi(k)+\frac{1}{2 \pi} \exp \left\{-\frac{\left(h_{1}^{2}+h_{2}^{2}\right)}{2}\right\} \sum_{j=0}^{\infty} \frac{2^{-j} \rho^{j+1}}{j+1 !} H_{j}\left(\frac{h_{1}}{\sqrt{2}}\right) H_{j}\left(\frac{h_{2}}{\sqrt{2}}\right),
$$

where

$$
L\left(h_{1}, h_{2}, \rho\right)=\Phi\left(-h_{1},-h_{2}, \rho\right)
$$

and $H_{j}(x)$ is the Hermite polynomial defined by Abramowitz and Stegun [1, p. 775]:

$$
\begin{gathered}
H_{j}(x)=(-1)^{j} \exp \left(x^{2}\right) D^{j} \exp \left(-x^{2}\right)=j ! \sum_{k=0}^{[j / 2]} \frac{(-1)^{k}}{k !(j-2 k) !}(2 x)^{j-2 k} \\
{[j / 2]= \begin{cases}j / 2 & j \text { even, } \\
(j-1) / 2 & j \text { odd },\end{cases} }
\end{gathered}
$$

Received by the editor June 28, 2012 and, in revised form, January 9, 2013.

2010 Mathematics Subject Classification. Primary 42A16, 62H86.

Key words and phrases. Multivariate normal probability integral, Fourier series, tetrachoric series. 
and $\Phi(x)$ is the standard univariate CDF given by

$$
\Phi(x)=\frac{1}{\sqrt{2 \pi}} \int_{-\infty}^{x} \exp \left(-\frac{t^{2}}{2}\right) d t .
$$

However, this series converges too slowly for large values of $|\rho|$ and thus is not very satisfactory. Owen [20] expressed the bivariate normal CDF in terms of the T-function as

$$
\Phi\left(h_{1}, h_{2}, \rho\right)=\frac{1}{2} \Phi\left(h_{1}\right)-T\left(h_{1}, \frac{h_{2}-\rho h_{1}}{h_{1} \sqrt{1-\rho^{2}}}\right)+\frac{1}{2} \Phi\left(h_{2}\right)-T\left(h_{2}, \frac{h_{1}-\rho h_{2}}{h_{2} \sqrt{1-\rho^{2}}}\right)+\eta,
$$

where

$$
\begin{gathered}
\eta=\left\{\begin{array}{r}
0 \quad \text { if } h_{1} h_{2}>0 \text { or if } h_{1} h_{2}=0 \text { but } h_{1}+h_{2} \geq 0, \\
-\frac{1}{2} \quad \text { otherwise, }
\end{array}\right. \\
T(h, a)=\frac{1}{2 \pi} \int_{0}^{a} \frac{1}{1+x^{2}} \exp \left\{-\frac{h^{2}}{2}\left(1+x^{2}\right)\right\} d x \\
=\frac{\arctan a}{2 \pi}-\frac{1}{2 \pi} \sum_{j=0}^{\infty} \frac{(-1)^{j} a^{2 j+1}}{2 j+1}\left[1-\exp \left(-\frac{h^{2}}{2}\right) \sum_{i=0}^{j} \frac{h^{2 i}}{2^{i} i !}\right] .
\end{gathered}
$$

Note that the T-function can also be written in terms of the normalized incomplete Gamma function [1, pp. 260, 262]:

$$
P(a, x)=\frac{1}{\Gamma(a)} \int_{0}^{x} t^{a-1} \exp (-t) d t=1-\exp (-x) \sum_{i=0}^{a-1} \frac{x^{i}}{i !}
$$

as

$$
T(h, a)=\frac{\arctan a}{2 \pi}-\frac{1}{2 \pi} \sum_{j=0}^{\infty} \frac{(-1)^{j} a^{2 j+1}}{2 j+1} P\left(j+1, \frac{h^{2}}{2}\right) .
$$

The series expansion of the T-function converges rapidly for small values of $a$ and $h$ but converges quite slowly when $h$ is large and $a$ is close to 1 . Donnelly [5] directly coded Owen's method and formed the Owen-Donnelly algorithm, which has been widely used as it gives the values of the bivariate normal CDF to 15 digit accuracy. Fayed and Atiya [8] derived two formulas that converge fast for large values of $|\rho|$. One of them, for $\rho<0$, is given by

$$
\begin{aligned}
L\left(h_{1}, h_{2}, \rho\right)= & L_{20}+\sum_{u=0}^{\infty}\left[\psi_{u}\left(b_{2}\right)+\psi_{u}\left(c_{2}\right)\right] \\
& \cdot\left\{\begin{array}{cl}
(-1)^{u}\left[1-P\left(\frac{u}{2}+1, z_{10}^{2}\right)\right] & h_{1}+h_{2} \geq 0, \\
{\left[(-1)^{u}-P\left(\frac{u}{2}+1, z_{10}^{2}\right)\right]} & h_{1}+h_{2}<0,
\end{array}\right.
\end{aligned}
$$

where

$$
\begin{gathered}
\psi_{u}(x)=\frac{1}{2 \sqrt{\pi} \Gamma\left(\frac{u}{2}+\frac{3}{2}\right)}\left(\frac{a_{2}}{2}\right)^{u+1} \exp \left(-x^{2}\right) H_{u}(x), \\
a_{2}=\sqrt{\frac{1+\rho}{1-\rho}}, b_{2}=\frac{-h_{2}}{\sqrt{1-\rho}}, c_{2}=\frac{-h_{1}}{\sqrt{1-\rho}}, z_{10}=\frac{h_{1}+h_{2}}{2 \sqrt{1+\rho}}, \\
L_{20}=\frac{1}{2}\left[\left(1-\operatorname{sign}\left(z_{10}\right)\left(2 \Phi\left(\sqrt{2}\left|z_{10}\right|\right)-1\right)\right)\left(1-\Phi\left(-\sqrt{2} b_{2}\right)-\Phi\left(-\sqrt{2} c_{2}\right)\right)\right],
\end{gathered}
$$


and another similar formula for $\rho>0$. There is another group of methods in the literature that are based on numerically approximating the integral. Among those methods, Divgi [4] estimated the complementary integral in polar coordinates. Drezner [6] provided different formulas based on a direct computation of the double integral using the Gauss quadrature method. Drezxner and Wesolowsky 7. presented a simple method that achieves single precision accuracy with less computation time than Divgi's algorithm. Genz [13] presented a modified form of the Dresner and Wesolowsky algorithm that is slightly more accurate for double precision.

For the multivariate case, $m>2$, Kendall 18 gives a generalization of the tetrachoric series, for the trivariate case,

$$
\begin{aligned}
& L\left(h_{1}, h_{2}, h_{3}, \rho_{12}, \rho_{13}, \rho_{23}\right)= \\
& \frac{\exp \left\{-\frac{h_{1}^{2}+h_{2}^{2}+h_{3}^{2}}{2}\right\}}{(\sqrt{2 \pi})^{3}} \sum_{i=0}^{\infty} \sum_{j=0}^{\infty} \sum_{k=0}^{\infty} \frac{2^{-i-j-k-1} \rho_{12}^{i} \rho_{23}^{j} \rho_{13}^{k}}{i ! j ! k !} H_{i+j-1}\left(\frac{h_{1}}{\sqrt{2}}\right) H_{i+k-1}\left(\frac{h_{2}}{\sqrt{2}}\right) H_{j+k-1}\left(\frac{h_{3}}{\sqrt{2}}\right)
\end{aligned}
$$

and for the quadrivariate case it can be written as

$$
\begin{aligned}
& L\left(h_{1}, h_{2}, h_{3}, h_{4}, \rho_{12}, \rho_{13}, \rho_{14}, \rho_{23}, \rho_{24}, \rho_{34}\right)= \\
& \frac{\exp \left\{-\frac{h_{1}^{2}+h_{2}^{2}+h_{3}^{2}+h_{4}^{2}}{2}\right\}}{(2 \pi)^{2}} \sum_{l=0}^{\infty} \sum_{m=0}^{\infty} \sum_{n=0}^{\infty} \sum_{o=0}^{\infty} \sum_{p=0}^{\infty} \sum_{q=0}^{\infty} \frac{2^{-l-m-n-o-p-q-2} \rho_{12}^{l} \rho_{13}^{m} \rho_{14}^{n} \rho_{23}^{o} \rho_{24}^{p} \rho_{34}^{q}}{l ! m ! n ! o ! p ! q !} \\
& \cdot H_{l+m+n-1}\left(\frac{h_{1}}{\sqrt{2}}\right) H_{l+o+p-1}\left(\frac{h_{2}}{\sqrt{2}}\right) H_{m+o+q-1}\left(\frac{h_{3}}{\sqrt{2}}\right) H_{n+p+q-1}\left(\frac{h_{4}}{\sqrt{2}}\right) .
\end{aligned}
$$

However, these series require computation of a number of summations of $O\left(\mathrm{~m}^{2}\right)$. Moreover, they are found to converge slowly when $\rho_{i j}>0.3$ and therefore are not satisfactory from a practical point of view (see numerical experiments section). A more computable case occurs when the components of $x$ are equicorrelated. If $\rho_{i j}=\rho$ for all $i \neq j, \rho_{i i}=1$, then the integral can be found by the formula [25, p. 192]:

$$
L(h, \Sigma)=\frac{1}{\sqrt{2 \pi}} \int_{-\infty}^{\infty} \exp \left(-\frac{t^{2}}{2}\right) \prod_{i=1}^{m} \Phi\left(\frac{-h_{i}+t \sqrt{\rho}}{\sqrt{1-\rho}}\right) d t
$$

There exist several numerical methods for the general case based on multivariate integration techniques that rely on ordinary Monte-Carlo methods along with some common variance reduction techniques. These include a method introduced by Deák [2, 3], which decomposes the multivariate normal distribution into two components, an $(m-1)$-dimensional direction and a one-dimensional length component, which can be integrated out explicitly. Another group of algorithms due to Szantai is based on computing upper and lower bounds on the probability (see [10,12, for a survey of these methods). Besides, Shephard [23] derived a framework to compute the distribution function from the characteristic function and developed numerical integration rules for the evaluation of the resultant integrals. Recently, Miwa et al. [19] proposed a method that is considered among the most efficient methods for $m \leq 7$. In this method, evaluation of the multiple integral is transformed into recursive evaluatation of a one-dimensional integration over a fine grid of points. 


\section{FOURIER SERIES APPROACH}

Assume that $h_{j} \in\left[-h_{\max }, h_{\max }\right]$ (for example $h_{\max }=4$ ), $j=1, \ldots, m$, then the multivariate probability integral can be approximated as

$$
L(h, \Sigma)=\frac{1}{\sqrt{(2 \pi)^{m}|\Sigma|}} \int_{-\infty}^{\infty} \ldots \int_{-\infty}^{\infty}\left[\prod_{j=1}^{m} g\left(x_{j}-h_{j}\right)\right] \exp \left\{-\frac{1}{2} x^{T} \Sigma^{-1} x\right\} d x
$$

where $g\left(x_{j}\right)$ is a periodic square wave function with period $2 T$ (where $T \geq 2 h_{\max }$ for good results) and the fundamental period is given by

$$
g\left(x_{j}\right)= \begin{cases}0 & -T<x_{j}<0 \\ 1 & 0 \leq x_{j} \leq T\end{cases}
$$

Using Cholesky decomposition of the covariance matrix as employed by Deák and Genz [2, 11]; that is, $\Sigma=C C^{T}$, and then using the transformation $x=C y$ and thereby $d x=|C| d y=|\Sigma|^{\frac{1}{2}} d y$ leads to

$$
L(h, \Sigma)=\frac{1}{\sqrt{(2 \pi)^{m}}} \int_{-\infty}^{\infty} \ldots \int_{-\infty}^{\infty}\left[\prod_{j=1}^{m} g\left(c_{j}^{T} y-h_{j}\right)\right] \exp \left\{-\frac{1}{2} y^{T} y\right\} d y
$$

where $C^{T}=\left[\begin{array}{llll}c_{1} & c_{2} & \cdots & c_{m}\end{array}\right]$.

Expanding $g\left(x_{j}\right)$ in the Fourier series

$$
\begin{aligned}
g\left(x_{j}\right) & =\frac{1}{2}+\frac{2}{\pi} \sum_{n_{j}=0}^{\infty} \frac{1}{\left(2 n_{j}+1\right)} \sin \left(\frac{\left(2 n_{j}+1\right) \pi\left(x_{j}\right)}{T}\right) \\
& =\frac{1}{2}-\frac{i}{\pi} \sum_{n_{j}=0}^{\infty} \frac{1}{\left(2 n_{j}+1\right)}\left[e^{\frac{\left(2 n_{j}+1\right) i \pi\left(x_{j}\right)}{T}}-e^{\frac{-\left(2 n_{j}+1\right) i \pi\left(x_{j}\right)}{T}}\right]
\end{aligned}
$$

and substituting in (2.1) leads to

$$
\begin{aligned}
L(h, \Sigma) & =\frac{1}{\sqrt{(2 \pi)^{m}}} \int_{-\infty}^{\infty} \ldots \int_{-\infty}^{\infty} \exp \left\{-\frac{1}{2} y^{T} y\right\} \\
& \cdot \prod_{j=1}^{m}\left\{\frac{1}{2}-\frac{i}{\pi} \sum_{n_{j}=0}^{\infty} \frac{1}{\left(2 n_{j}+1\right)}\left[e^{\frac{\left(2 n_{j}+1\right) i \pi\left(c_{j}^{T} y-h_{j}\right)}{T}}-e^{\frac{-\left(2 n_{j}+1\right) i \pi\left(c_{j}^{T} y-h_{j}\right)}{T}}\right]\right\} d y
\end{aligned}
$$

The above multiple integral can be expressed as sums of products of single integrals for each variable $y_{j}$ where each one can be evaluated using the following integral [22, p. 459]:

$$
\frac{1}{\sqrt{2 \pi}} \int_{-\infty}^{\infty} e^{\frac{-x^{2}}{2}+i(q x+r)} d x=e^{\frac{-q^{2}}{2}+i r}
$$

Note that the complexity of the resultant terms ranges from a constant term which is $\frac{1}{2^{m}}$ to the most complicated term which is composed of $m$ nested summations. 


\section{Bivariate case}

For the bivariate case, we have

$$
\Sigma=\left[\begin{array}{ll}
1 & \rho \\
\rho & 1
\end{array}\right] \text { and } C=\left[\begin{array}{ll}
1 & 0 \\
\rho & \sqrt{1-\rho^{2}}
\end{array}\right]
$$

Therefore, the complementary integral can be written as

$$
\begin{aligned}
L\left(h_{1}, h_{2}, \rho\right)= & \frac{1}{2 \pi} \int_{-\infty}^{\infty} \int_{-\infty}^{\infty} e^{\frac{-y_{1}^{2}-y_{2}^{2}}{2}} \\
& \cdot\left\{\frac{1}{2}-\frac{i}{\pi} \sum_{n_{1}=0}^{\infty} \frac{1}{\left(2 n_{1}+1\right)} \cdot\right. \\
& {\left.\left[e^{\frac{\left(2 n_{1}+1\right) i \pi\left(y_{1}-h_{1}\right)}{T}}-e^{\frac{-\left(2 n_{1}+1\right) i \pi\left(y_{1}-h_{1}\right)}{T}}\right]\right\} } \\
& \left.\cdot\left\{\frac{1}{2}-\frac{i}{\pi} \sum_{n_{2}=0}^{\infty} \frac{1}{\left(2 n_{2}+1\right)}\right]\right\} \\
& {\left.\left[e^{\frac{\left(2 n_{2}+1\right) i \pi\left(\rho y_{1}+\sqrt{1-\rho^{2}} y_{2}-h_{2}\right)}{T}}-e^{\frac{-\left(2 n_{2}+1\right) i \pi\left(\rho y_{1}+\sqrt{1-\rho^{2}} y_{2}-h_{2}\right)}{T}}\right]\right\} }
\end{aligned}
$$

$d y_{1} d y_{2}$.

Using (2.2), it can be shown that

$$
\begin{aligned}
L\left(h_{1}, h_{2}, \rho\right)= & \frac{1}{4} \\
& -\frac{1}{\pi} \sum_{n_{1}=0}^{\infty} \frac{e^{\frac{-\pi^{2}}{2 T^{2}}\left(2 n_{1}+1\right)^{2}}}{\left(2 n_{1}+1\right)}\left\{\sin \left(\frac{\left(2 n_{1}+1\right) \pi h_{1}}{T}\right)+\sin \left(\frac{\left(2 n_{1}+1\right) \pi h_{2}}{T}\right)\right\} \\
& -\frac{2}{\pi^{2}} \sum_{n_{1}=0}^{\infty} \sum_{n_{2}=0}^{\infty} \frac{e^{\frac{-\pi^{2}}{2 T^{2}}\left\{\left(2 n_{1}+1\right)^{2}+\left(2 n_{2}+1\right)^{2}\right\}}}{\left(2 n_{1}+1\right)\left(2 n_{2}+1\right)} \\
& \cdot\left\{e^{\frac{-\pi^{2}}{T^{2}}\left(2 n_{1}+1\right)\left(2 n_{2}+1\right) \rho} \cos \left(\frac{\pi}{T}\left[\left(2 n_{1}+1\right) h_{1}+\left(2 n_{2}+1\right) h_{2}\right]\right)\right. \\
& \left.-e^{\frac{\pi^{2}}{T^{2}}\left(2 n_{1}+1\right)\left(2 n_{2}+1\right) \rho} \cos \left(\frac{\pi}{T}\left[\left(2 n_{1}+1\right) h_{1}-\left(2 n_{2}+1\right) h_{2}\right]\right)\right\} .
\end{aligned}
$$

Note that, for the special case when $\rho=0, h_{2}=0$, we have

$$
L\left(h_{1}, 0,0\right)=\frac{1}{4}-\frac{1}{\pi} \sum_{n_{1}=0}^{\infty} \frac{e^{\frac{-\pi^{2}}{2 T^{2}}\left(2 n_{1}+1\right)^{2}}}{\left(2 n_{1}+1\right)} \sin \left(\frac{\left(2 n_{1}+1\right) \pi h_{1}}{T}\right)
$$

which is known to be [21]:

$$
L\left(h_{1}, 0,0\right)=\frac{1}{2} \Phi\left(-h_{1}\right)=\frac{1}{4}-\frac{1}{4} \operatorname{erf}\left(\frac{h_{1}}{\sqrt{2}}\right) .
$$


So we can conclude that

$$
\operatorname{erf}\left(\frac{h_{1}}{\sqrt{2}}\right)=\frac{4}{\pi} \sum_{n_{1}=0}^{\infty} \frac{e^{\frac{-\pi^{2}}{2 T^{2}}\left(2 n_{1}+1\right)^{2}}}{\left(2 n_{1}+1\right)} \sin \left(\frac{\left(2 n_{1}+1\right) \pi h_{1}}{T}\right)
$$

which is actually the Fourier series expansion of a periodic function of $\operatorname{erf}\left(h_{1} / \sqrt{2}\right)$ with a fundamental period $[-T, T]$. Therefore the bivariate complementary integral can be written as

$$
\begin{aligned}
L\left(h_{1}, h_{2}, \rho\right)= & \frac{1}{4}-\frac{1}{4} \operatorname{erf}\left(\frac{h_{1}}{\sqrt{2}}\right)-\frac{1}{4} \operatorname{erf}\left(\frac{h_{2}}{\sqrt{2}}\right) \\
& -\frac{2}{\pi^{2}} \sum_{n_{1}=0}^{\infty} \sum_{n_{2}=0}^{\infty} \frac{e^{\frac{-\pi^{2}}{2 T^{2}}\left\{\left(2 n_{1}+1\right)^{2}+\left(2 n_{2}+1\right)^{2}\right\}}}{\left(2 n_{1}+1\right)\left(2 n_{2}+1\right)} \\
& \cdot\left\{e^{\frac{-\pi^{2}}{T^{2}}\left(2 n_{1}+1\right)\left(2 n_{2}+1\right) \rho} \cos \left(\frac{\pi}{T}\left[\left(2 n_{1}+1\right) h_{1}+\left(2 n_{2}+1\right) h_{2}\right]\right)\right. \\
& \left.-e^{\frac{\pi^{2}}{T^{2}}\left(2 n_{1}+1\right)\left(2 n_{2}+1\right) \rho} \cos \left(\frac{\pi}{T}\left[\left(2 n_{1}+1\right) h_{1}-\left(2 n_{2}+1\right) h_{2}\right]\right)\right\}
\end{aligned}
$$

Since the bivariate normal CDF can be expressed as [1, 9]:

$$
\begin{aligned}
\Phi\left(h_{1}, h_{2}, \rho\right) & =\Phi\left(h_{1}, 0, \frac{\left(\rho h_{1}-h_{2}\right) \operatorname{sign}\left(h_{1}\right)}{\sqrt{h_{1}^{2}-2 \rho h_{1} h_{2}+h_{2}^{2}}}\right)+\Phi\left(h_{2}, 0, \frac{\left(\rho h_{2}-h_{1}\right) \operatorname{sign}\left(h_{2}\right)}{\sqrt{h_{1}^{2}-2 \rho h_{1} h_{2}+h_{2}^{2}}}\right) \\
& -\left[\begin{array}{cc}
0 & \text { if } h_{1} h_{2}>0 \\
\frac{1}{2} & \text { if } h_{1} h_{2}<0
\end{array}\right] .
\end{aligned}
$$

Therefore we can study the special case when $h_{2}=0$, so for the above Fourier series, we have

$$
\begin{aligned}
L\left(h_{1}, 0, \rho\right) & =\frac{1}{4} \operatorname{erfc}\left(\frac{h_{1}}{\sqrt{2}}\right) \\
& +\frac{4}{\pi^{2}} \sum_{n_{1}=0}^{\infty} \sum_{n_{2}=0}^{\infty} \frac{e^{\frac{-\pi^{2}}{2 T^{2}}\left\{\left(2 n_{1}+1\right)^{2}+\left(2 n_{2}+1\right)^{2}\right\}}}{\left(2 n_{1}+1\right)\left(2 n_{2}+1\right)} \sinh \left[\frac{\pi^{2} \rho}{T^{2}}\left(2 n_{1}+1\right)\left(2 n_{2}+1\right)\right] \\
& \cdot \cos \left[\frac{\pi h_{1}}{T}\left(2 n_{1}+1\right)\right] .
\end{aligned}
$$

It is found that convergence of the above series is good only for small values of $|\rho|$. In the following subsection we will derive other forms of this series, one of them converges fast for all values of $\rho$.

3.1. Different forms of the bivariate case. Let us investigate other forms of the above formula. First, note that for the special case when $h_{1}=h_{2}=0$, and comparing with the well-known formula of Johnson and Kotz [17, we can conclude that

$$
\arcsin \rho=\frac{8}{\pi} \sum_{n_{1}=0}^{\infty} \sum_{n_{2}=0}^{\infty} \frac{e^{\frac{-\pi^{2}}{2 T^{2}}\left\{\left(2 n_{1}+1\right)^{2}+\left(2 n_{2}+1\right)^{2}\right\}}}{\left(2 n_{1}+1\right)\left(2 n_{2}+1\right)} \sinh \left[\frac{\pi^{2} \rho}{T^{2}}\left(2 n_{1}+1\right)\left(2 n_{2}+1\right)\right] .
$$


Using the Maclaurin series of the inverse sine and hyperbolic sine functions,

$$
\begin{aligned}
\sum_{j=0}^{\infty} \frac{2 j !}{2^{2 j} j !^{2}(2 j+1)} \rho^{2 j+1} & =\frac{8}{\pi} \sum_{j=0}^{\infty} \sum_{n_{1}=0}^{\infty} \sum_{n_{2}=0}^{\infty} \frac{e^{\frac{-\pi^{2}}{2 T^{2}}\left\{\left(2 n_{1}+1\right)^{2}+\left(2 n_{2}+1\right)^{2}\right\}}}{\left(2 n_{1}+1\right)\left(2 n_{2}+1\right)(2 j+1) !} \\
& \cdot\left[\frac{\pi^{2} \rho}{T^{2}}\left(2 n_{1}+1\right)\left(2 n_{2}+1\right)\right]^{2 j+1} \cdot
\end{aligned}
$$

By comparing the coefficient of $\rho^{2 j+1}$ in both sides, we have

$$
\sum_{n_{1}=0}^{\infty}\left(2 n_{1}+1\right)^{2 j} e^{\frac{-\pi^{2}}{2 T^{2}}\left(2 n_{1}+1\right)^{2}}=\left(\frac{T}{\pi}\right)^{2 j+1} 2^{j-\frac{3}{2}} \Gamma\left(j+\frac{1}{2}\right) .
$$

By differentiating (3.1), $2 j+1$ times, we can conclude that

$$
\begin{aligned}
\sum_{n_{1}=0}^{\infty}(-1)^{j}\left(2 n_{1}\right. & +1)^{2 j} e^{\frac{-\pi^{2}}{2 T^{2}}\left(2 n_{1}+1\right)^{2}} \cos \left(\frac{\left(2 n_{1}+1\right) \pi h_{1}}{T}\right) \\
& =\frac{1}{2} \sqrt{\frac{\pi}{2}}\left(\frac{T}{\pi}\right)^{2 j+1} \frac{d^{2 j}}{d h_{1}^{2 j}}\left\{\exp \left(-\frac{h_{1}^{2}}{2}\right)\right\} .
\end{aligned}
$$

Using the definition of the Hermite polynomial [1, p. 785], it can be written as

$$
\begin{array}{r}
\sum_{n_{1}=0}^{\infty}(-1)^{j}\left(2 n_{1}+1\right)^{2 j} e^{\frac{-\pi^{2}}{2 T^{2}}\left(2 n_{1}+1\right)^{2}} \cos \left(\frac{\left(2 n_{1}+1\right) \pi h_{1}}{T}\right) \\
=\sqrt{\pi}\left(\frac{T}{\pi}\right)^{2 j+1} 2^{-j-\frac{3}{2}} \exp \left(-\frac{h^{2}}{2}\right) H_{2 j}\left(\frac{h}{\sqrt{2}}\right) .
\end{array}
$$

Substituting by (3.4) and (3.5) in (3.3), we get

$$
L\left(h_{1}, 0, \rho\right)=\frac{1}{4} \operatorname{erfc}\left(\frac{h_{1}}{\sqrt{2}}\right)+\frac{1}{2 \pi} \exp \left(-\frac{h^{2}}{2}\right) \sum_{j=0}^{\infty} \frac{(-1)^{j} 2^{-2 j} \rho^{2 j+1}}{j !(2 j+1)} H_{2 j}\left(\frac{h_{1}}{\sqrt{2}}\right),
$$

which is actually the tetrachoric series 21. It is also known that it converges fast for small values of $|\rho|$ but it is very slow when $|\rho|$ is close to 1 .

Another form can be obtained as follows:

$$
\begin{aligned}
L\left(h_{1}, 0, \rho\right)= & \frac{1}{4} \operatorname{erfc}\left(\frac{h_{1}}{\sqrt{2}}\right) \\
+ & \frac{4}{\pi^{2}} \sum_{n_{1}=0}^{\infty} \frac{e^{\frac{-\pi^{2}}{2 T^{2}}\left(2 n_{1}+1\right)^{2}}}{\left(2 n_{1}+1\right)} \cos \left[\frac{\pi h_{1}}{T}\left(2 n_{1}+1\right)\right] \\
& \cdot \sum_{j=0}^{\infty} \frac{2^{j-\frac{3}{2}} \Gamma\left(j+\frac{1}{2}\right)}{(2 j+1) !}\left[\frac{\pi \rho}{T}\left(2 n_{1}+1\right)\right]^{2 j+1} .
\end{aligned}
$$

Using the definition of Dawson function, [1, p. 298],

$$
\operatorname{Daw}(x)=\exp \left(-x^{2}\right) \int_{0}^{x} \exp \left(t^{2}\right) d t=\exp \left(-x^{2}\right) \sum_{j=0}^{\infty} \frac{x^{2 j+1}}{j !(2 j+1)},
$$


we get

$$
\begin{aligned}
L\left(h_{1}, 0, \rho\right) & =\frac{1}{4} \operatorname{erfc}\left(\frac{h_{1}}{\sqrt{2}}\right) \\
& +\frac{2}{\pi \sqrt{\pi}} \sum_{n_{1}=0}^{\infty} \frac{e^{\frac{-\pi^{2}\left(1-\rho^{2}\right)}{2 T^{2}}\left(2 n_{1}+1\right)^{2}}}{\left(2 n_{1}+1\right)} \operatorname{Daw}\left[\frac{\pi \rho}{\sqrt{2} T}\left(2 n_{1}+1\right)\right] \\
& \cdot \cos \left[\frac{\pi h_{1}}{T}\left(2 n_{1}+1\right)\right] .
\end{aligned}
$$

Note that the above series is convergent, since the non-alternating series (say $\mathrm{S}$ )

$$
\begin{aligned}
|S| & \leq \frac{2}{\pi \sqrt{\pi}} \sum_{n_{1}=0}^{\infty} \frac{e^{\frac{-\pi^{2}\left(1-\rho^{2}\right)}{2 T^{2}}\left(2 n_{1}+1\right)^{2}}}{\left(2 n_{1}+1\right)}\left|\operatorname{Daw}\left[\frac{\pi \rho}{\sqrt{2} T}\left(2 n_{1}+1\right)\right]\right| \\
& \leq \frac{2(0.55)}{\pi \sqrt{\pi}} \sum_{n_{1}=0}^{\infty} \frac{e^{\frac{-\pi^{2}\left(1-\rho^{2}\right)}{2 T^{2}}\left(2 n_{1}+1\right)^{2}}}{\left(2 n_{1}+1\right)} \\
& \leq \frac{1.1}{\pi \sqrt{\pi}} \sum_{n_{1}=0}^{\infty} \frac{e^{\frac{-\pi^{2}\left(1-\rho^{2}\right)}{2 T^{2}}\left(2 n_{1}+1\right)}}{\left(2 n_{1}+1\right)}=\frac{0.55}{\pi \sqrt{\pi}} \ln \left[\frac{1+e^{\frac{-\pi^{2}\left(1-\rho^{2}\right)}{2 T^{2}}}}{1-e^{\frac{-\pi^{2}\left(1-\rho^{2}\right)}{2 T^{2}}}}\right],
\end{aligned}
$$

where we have used $|\operatorname{Daw}(x)| \leq 0.55$ and $\sum_{n=0}^{\infty} \frac{x^{2 n+1}}{2 n+1}=\frac{1}{2} \ln \left[\frac{1+x}{1-x}\right],|x|<1$.

Note also that $\operatorname{Daw}(0)=0$ and it increases until reaching its maximum value (which is less than 0.55) and then decreases and approaches zero as $x$ tends to $\infty$ [1, p. 297]; see Figure 1. Therefore it converges faster than the tetrachoric series for large values for $|\rho|$.

\section{Multivariate CASE}

For the trivariate case, using the special shape of the Cholesky decomposition, it can be shown that

$$
\begin{gathered}
L\left(h_{1}, h_{2}, h_{3}, \rho_{12}, \rho_{13}, \rho_{23}\right)=L_{0}+L_{1}+L_{2}+L_{3}, \\
L_{0}=\frac{1}{8}, \quad L_{1}=-\frac{1}{8}\left[\operatorname{erf}\left(\frac{h_{1}}{\sqrt{2}}\right)+\operatorname{erf}\left(\frac{h_{2}}{\sqrt{2}}\right)+\operatorname{erf}\left(\frac{h_{3}}{\sqrt{2}}\right)\right], \\
L_{2}=-\frac{1}{\pi^{2}} \sum_{j>i} \sum_{n_{i}=0}^{\infty} \sum_{n_{j}=0}^{\infty} \frac{e^{\frac{-\pi^{2}}{2 T^{2}}\left\{\left(2 n_{i}+1\right)^{2}+\left(2 n_{j}+1\right)^{2}\right\}}}{\left(2 n_{i}+1\right)\left(2 n_{j}+1\right)} \\
\cdot \sum_{s=0}^{1}\left\{(-1)^{s} e^{\frac{-(-1)^{s} \pi^{2}}{T^{2}}\left\{\rho_{i j}\left(2 n_{i}+1\right)\left(2 n_{j}+1\right)\right\}}\right. \\
\left.\cos \left(\frac{\pi}{T}\left[\left(2 n_{i}+1\right) h_{i}+(-1)^{s}\left(2 n_{j}+1\right) h_{j}\right]\right)\right\}
\end{gathered}
$$




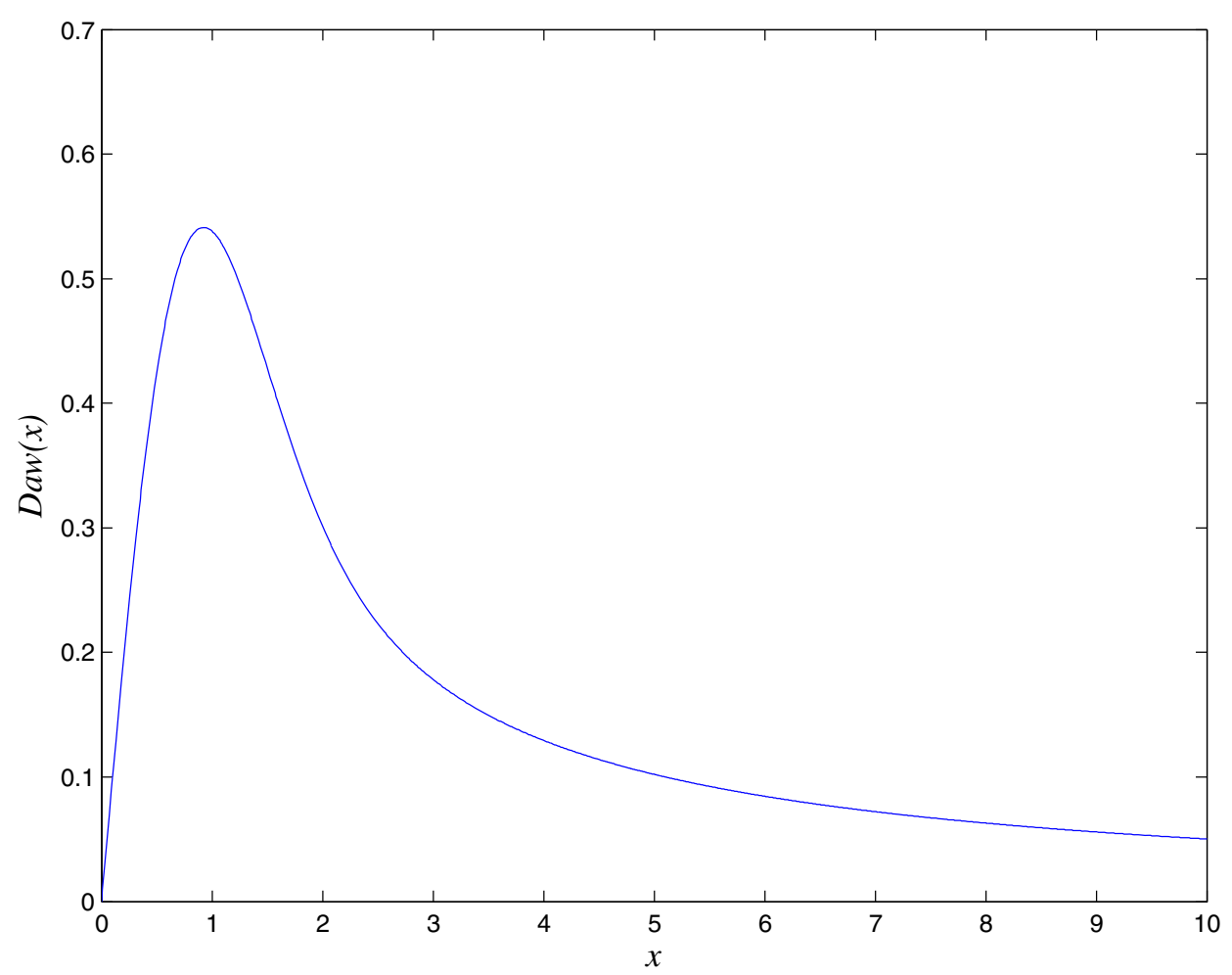

Figure 1. Dawson function

$$
\begin{aligned}
L_{3} & =\frac{2}{\pi^{3}} \sum_{k>j>i} \sum_{n_{i}=0}^{\infty} \sum_{n_{j}=0}^{\infty} \sum_{n_{k}=0}^{\infty} \frac{e^{\frac{-\pi^{2}}{2 T^{2}}\left\{\left(2 n_{i}+1\right)^{2}+\left(2 n_{j}+1\right)^{2}+\left(2 n_{k}+1\right)^{2}\right\}}}{\left(2 n_{i}+1\right)\left(2 n_{j}+1\right)\left(2 n_{k}+1\right)} \\
& \cdot \sum_{s_{i}, s_{j}, s_{k}=\{0,1\}, s_{i}+s_{j}+s_{k} \leq 1}(-1)^{\sum_{a \in\{i, j, k\}} s_{a}} e^{\frac{-\pi^{2}}{T^{2}}} \sum_{a, b \in\{i, j, k\}, a \neq b}(-1)^{s_{a}+s_{b}\left(2 n_{a}+1\right)\left(2 n_{b}+1\right) \rho_{a b}} \\
& \left.\cdot \sin \left(\frac{\pi}{T} \sum_{a \in\{i, j, k\}}(-1)^{s_{a}}\left(2 n_{a}+1\right) h_{a}\right)\right\}
\end{aligned}
$$

and for the quadrivariate case

$$
\begin{aligned}
& L\left(h_{1}, h_{2}, h_{3}, h_{4}, \rho_{12}, \rho_{13}, \rho_{14}, \rho_{23}, \rho_{24}, \rho_{34}\right)=L_{0}+L_{1}+L_{2}+L_{3}+L_{4}, \\
& L_{0}=\frac{1}{16}, \quad L_{1}=-\frac{1}{16}\left[\operatorname{erf}\left(\frac{h_{1}}{\sqrt{2}}\right)+\operatorname{erf}\left(\frac{h_{2}}{\sqrt{2}}\right)+\operatorname{erf}\left(\frac{h_{3}}{\sqrt{2}}\right)+\operatorname{erf}\left(\frac{h_{4}}{\sqrt{2}}\right)\right],
\end{aligned}
$$




$$
\begin{aligned}
& L_{2}=-\frac{1}{2 \pi^{2}} \sum_{j>i} \sum_{n_{i}=0}^{\infty} \sum_{n_{j}=0}^{\infty} \frac{e^{\frac{-\pi^{2}}{2 T^{2}}\left\{\left(2 n_{i}+1\right)^{2}+\left(2 n_{j}+1\right)^{2}\right\}}}{\left(2 n_{i}+1\right)\left(2 n_{j}+1\right)} \\
& \cdot \sum_{s=0}^{1}\left\{(-1)^{s} e^{\frac{-(-1)^{s} \pi^{2}}{T^{2}}\left\{\rho_{i j}\left(2 n_{i}+1\right)\left(2 n_{j}+1\right)\right\}}\right. \\
& \left.\cos \left(\frac{\pi}{T}\left[\left(2 n_{i}+1\right) h_{i}+(-1)^{s}\left(2 n_{j}+1\right) h_{j}\right]\right)\right\}, \\
& L_{3}=\frac{1}{\pi^{3}} \sum_{k>j>i} \sum_{n_{i}=0}^{\infty} \sum_{n_{j}=0}^{\infty} \sum_{n_{k}=0}^{\infty} \frac{e^{\frac{-\pi^{2}}{2 T^{2}}\left\{\left(2 n_{i}+1\right)^{2}+\left(2 n_{j}+1\right)^{2}+\left(2 n_{k}+1\right)^{2}\right\}}}{\left(2 n_{i}+1\right)\left(2 n_{j}+1\right)\left(2 n_{k}+1\right)} \\
& \sum_{s_{i}, s_{j}, s_{k}=\{0,1\}, s_{i}+s_{j}+s_{k} \leq 1}(-1)^{\sum_{a \in\{i, j, k\}} s_{a}} e^{\frac{-\pi^{2}}{T^{2}}} \sum_{a, b \in\{i, j, k\}, a \neq b}^{\sum(-1)^{s_{a}+s_{b}}\left(2 n_{a}+1\right)\left(2 n_{b}+1\right) \rho_{a b}} \\
& \left.\cdot \sin \left(\frac{\pi}{T} \sum_{a \in\{i, j, k\}}(-1)^{s_{a}}\left(2 n_{a}+1\right) h_{a}\right)\right\} \text {, } \\
& L_{4}=\frac{2}{\pi^{4}} \sum_{l>k>j} \sum_{n_{i}=0}^{\infty} \sum_{n_{j}=0}^{\infty} \sum_{n_{k}=0}^{\infty} \sum_{n_{l}=0}^{\infty} \frac{e^{\frac{-\pi^{2}}{2 T^{2}}\left\{\left(2 n_{i}+1\right)^{2}+\left(2 n_{j}+1\right)^{2}+\left(2 n_{k}+1\right)^{2}+\left(2 n_{l}+1\right)^{2}\right\}}}{\left(2 n_{i}+1\right)\left(2 n_{j}+1\right)\left(2 n_{k}+1\right)\left(2 n_{l}+1\right)} \\
& \cdot \sum_{\substack{s_{i}, s_{j}, s_{k}, s_{l}=\{0,1\}, s_{i}+s_{j}+s_{k}+s_{l} \leq 2}}(-1)^{\sum_{a \in\{i, j, k, l\}} s_{a}} e^{-\frac{\pi^{2}}{T^{2}}} \sum_{a, b \in\{i, j, k, l\}, a \neq b}(-1)^{s_{a}+s_{b}}\left(2 n_{a}+1\right)\left(2 n_{b}+1\right) \rho_{a b} \\
& \cdot \cos \left(\frac{\pi}{T} \sum_{a \in\{i, j, k, l\}}(-1)^{s_{a}}\left(2 n_{a}+1\right) h_{a}\right),
\end{aligned}
$$

where either $s_{a}=s_{b}=1$ or $s_{a}=s_{b}=0$ for $a, b \in\{i, j, k, l\}$ is selected when $s_{i}+s_{j}+s_{k}+s_{l}=2$ in $L_{4}$. Following the same procedure, it can be extended for any dimension.

\section{NumericAl EXPERIMENTS}

We compared the well-known tetrachoric series (Tetrachoric) with the newly derived Dawson series (Dawson), (3.6), and Fourier series (Fourier), (3.2), for the bivariate complementary integral. As our benchmark, We selected the Owen-Donnelly algorithm (Owen), since it has been considered the most widely implemented with 15 significant digits accuracy [5], and the Drezner-Wesolowsky method [7] with slightly improved version implemented by Genz [13] which is one of the most efficient methods currently available in double precision. A sample of 50 sets of values of $h_{1}$ is chosen uniformly from $[0, \sqrt{2}]$ for each $\rho$ ranges from $\{0.1,0.2, \ldots, 0.9\}$ while setting $h_{2}=0$. For Dawson and Fourier series, the half period length, $T$, is set to 10 . For Tetrachoric, Dawson and Owen methods, we examined the partial sums until an accuracy of $10^{-15}$ is obtained or the maximum number of terms (100 in our experiments) is reached. For Fourier series, we examined partial sums of the first $N=8$ and $N=12$ terms. We used C language in our implementation on Windows XP with SP2 running on Pentium $2.4 \mathrm{GHz}$ PC with $3 \mathrm{~GB}$ RAM. Dawson function is obtained from "Mathematics Source Library" available 
at: http://www.mymathlib.com. The average absolute error $\left(\right.$ Error $\left._{a v}\right)$ and the average number of terms $\left(N_{a v}\right)$ and their standard deviations required in Tetrachoric, Dawson and Owen methods over the experimental range of $h_{1}$ is reported in Table [1. The average time for each algorithm was less than $10^{-4}$, so it is not reported. It can be noticed from the results that Dawson series converges for all values of $\rho$. Moreover, it requires fewer number of terms to converge than the tetrachoric series especially for large values of $|\rho|$. On the other hand, Fourier series attains an average error less than $10^{-6}$ for $\rho \leq 0.6$ using $N=8$ terms and of order $10^{-12}$ for $\rho \leq 0.7$ using $N=12$.

TABlE 1. Bivariate results. Average absolute error $\left(\right.$ Error $\left._{a v}\right)$ and the average number of added terms $\left(N_{a v}\right)$ for Tetrachoric, Dawson and Owen methods. $N$ is the preset number of added terms for Fourier methods. Second row for each value of $\rho$ represents the standard deviation of the corresponding entry.

\begin{tabular}{|c|c|c|c|c|c|c|c|c|}
\hline \multirow{3}{*}{$\rho$} & \multicolumn{2}{|c|}{ Tetrachoric } & \multicolumn{2}{|c|}{ Dawson } & \multicolumn{2}{|c|}{ Fourier } & \multirow{3}{*}{$\begin{array}{c}\text { Genz } \\
\text { Error }_{a v}\end{array}$} & \multirow{3}{*}{$\begin{array}{l}\text { Owen } \\
N_{a v}\end{array}$} \\
\hline & \multirow{2}{*}{ Error $_{a v}$} & \multirow{2}{*}{$N_{a v}$} & \multirow{2}{*}{ Error $_{a v}$} & \multirow{2}{*}{$N_{a v}$} & Err & $p r_{a v}$ & & \\
\hline & & & & & $N=8$ & $N=12$ & & \\
\hline \multirow[t]{2}{*}{0.10} & $2.4 \mathrm{E}-017$ & 15 & $1.7 \mathrm{E}-017$ & 13 & $4.3 \mathrm{E}-009$ & $1.50 \mathrm{E}-15$ & $2.1 \mathrm{E}-016$ & 7 \\
\hline & 2.3E-017 & 0 & $1.8 \mathrm{E}-017$ & 0 & 2.9E-009 & $1.10 \mathrm{E}-15$ & $6.3 \mathrm{E}-016$ & 1 \\
\hline \multirow[t]{2}{*}{0.20} & 2.9E-017 & 22 & $1.4 \mathrm{E}-017$ & 13 & $9.5 \mathrm{E}-009$ & $2.90 \mathrm{E}-15$ & $9.7 \mathrm{E}-017$ & 8 \\
\hline & $2.8 \mathrm{E}-017$ & 1 & $1.7 \mathrm{E}-017$ & 0 & 8.1E-009 & $1.90 \mathrm{E}-15$ & $2.1 \mathrm{E}-016$ & 2 \\
\hline \multirow[t]{2}{*}{0.30} & $2.9 \mathrm{E}-017$ & 29 & $3.1 \mathrm{E}-017$ & 13 & 2.3E-008 & $2.00 \mathrm{E}-15$ & $1.2 \mathrm{E}-016$ & 8 \\
\hline & $3.6 \mathrm{E}-017$ & 0 & $3.2 \mathrm{E}-017$ & 0 & $1.6 \mathrm{E}-008$ & $1.90 \mathrm{E}-15$ & $2.8 \mathrm{E}-016$ & 2 \\
\hline \multirow[t]{2}{*}{0.40} & 3.7E-017 & 39 & $2.2 \mathrm{E}-017$ & 13 & 4.3E-008 & $3.40 \mathrm{E}-15$ & $1.4 \mathrm{E}-016$ & 9 \\
\hline & 4.1E-017 & 1 & $2.4 \mathrm{E}-017$ & 0 & 3.5E-008 & $2.80 \mathrm{E}-15$ & $2.5 \mathrm{E}-016$ & 2 \\
\hline \multirow[t]{2}{*}{0.50} & $3.3 \mathrm{E}-017$ & 51 & $3.2 \mathrm{E}-017$ & 15 & $1.2 \mathrm{E}-007$ & $1.40 \mathrm{E}-14$ & $1.2 \mathrm{E}-015$ & 10 \\
\hline & $3.2 \mathrm{E}-017$ & 0 & 3.7E-017 & 0 & $8.2 \mathrm{E}-008$ & $1.50 \mathrm{E}-14$ & $8.3 \mathrm{E}-015$ & 3 \\
\hline \multirow[t]{2}{*}{0.60} & $3.8 \mathrm{E}-017$ & 70 & 3.7E-017 & 15 & $4.8 \mathrm{E}-007$ & $6.80 \mathrm{E}-14$ & $1.4 \mathrm{E}-016$ & 11 \\
\hline & $3.9 \mathrm{E}-017$ & 1 & $3.8 \mathrm{E}-017$ & 0 & $4.0 \mathrm{E}-007$ & $1.40 \mathrm{E}-13$ & $4.2 \mathrm{E}-016$ & 4 \\
\hline \multirow[t]{2}{*}{0.70} & 4.4E-017 & 100 & $3.5 \mathrm{E}-017$ & 17 & $2.9 \mathrm{E}-006$ & $3.20 \mathrm{E}-12$ & $4.1 \mathrm{E}-017$ & 13 \\
\hline & $3.9 \mathrm{E}-017$ & 0 & $3.6 \mathrm{E}-017$ & 0 & $1.8 \mathrm{E}-006$ & $2.90 \mathrm{E}-12$ & $3.2 \mathrm{E}-017$ & 4 \\
\hline \multirow[t]{2}{*}{0.80} & 2.9E-014 & 100 & $6.2 \mathrm{E}-017$ & 21 & $2.5 \mathrm{E}-005$ & $1.20 \mathrm{E}-09$ & $9.9 \mathrm{E}-017$ & 13 \\
\hline & 1.6E-014 & 0 & $5.4 \mathrm{E}-017$ & 1 & $1.3 \mathrm{E}-005$ & 1.10E-09 & $1.4 \mathrm{E}-016$ & 4 \\
\hline \multirow[t]{2}{*}{0.90} & 7.3E-009 & 100 & $6.9 \mathrm{E}-017$ & 28 & $2.5 \mathrm{E}-004$ & $6.50 \mathrm{E}-07$ & $1.1 \mathrm{E}-016$ & 13 \\
\hline & 4.2E-009 & 0 & $4.9 \mathrm{E}-017$ & 1 & $1.4 \mathrm{E}-004$ & 4.60E-07 & $1.2 \mathrm{E}-016$ & 4 \\
\hline
\end{tabular}

We also compared the Fourier series approach for higher dimension (FORMVN). We applied it for $3 \leq m \leq 7$ cases and compared it with the tetrachoric series $(T E T M V N)$, Genz's subregion adaptive partitioning algorithm $(S A D M V N)$ and Genz's implementation of randomized Korobov rules (KROMVN) and Miwa's algorithm (Miwa). As a benchmark, we used the Gauss-Kronrod $(7,15)$ pair quadrature integration method for the equicorrelated case [25]. We implemented FOR$M V N$ and TETMVN in C language, and obtained the $\mathrm{C}$ code of Miwa's algorithm and the FORTRAN code of SADMVN and KROMVN from Genz's homepage (http://www.math.wsu.edu/faculty/genz/homepage). For the trivariate case, we compared also with Plackett's formula implemented by Genz [13. A sample of 
50 sets of values of $h_{i}^{\prime} s$ are chosen uniformly from $[0, \sqrt{m}]$ for each $\rho$ ranges from $\{0.1,0.2, \ldots, 0.9\}$. For FORMVN, TETMVN partial sums of the first $N=8$ and $N=12$ terms are considered for each summation and the half period length, $T$, is set to 10 for FORMVN. For SADMVN and KROMVN, the required accuracy is set to $10^{-8}$. For Miwa's algorithm, grid sizes examined are $G=128$ and $G=4096$ (which is the maximum that could be used due to memory limitation). The average absolute error, the average elapsed time and their standard deviations over the 50 runs are reported in Table 2 to Table11. It can be noticed that TETMVN is quite fast and has a good accuracy only for $m=3$ when $\rho \leq 0.4$ and for $m=4$ when $\rho \leq 0.3$ and in general FORMVN and Miwa's algorithms are significantly faster than $S A D M V N$ and $K R O M V N$ where FORMVN beats for $3 \leq m \leq 5$ when $\rho \leq 0.5$ while Miwa's algorithm beats for the other cases. Specifically, for $m=3$, Plackett method has the best accuracy and speed followed by FORMVN with $N=12$ for $\rho \leq 0.5$ and Miwa with $G=4096$ for $\rho>0.5$. For $m=4$ and $m=5$, FORMVN with $N=12$ has the best accuracy and speed for $\rho \leq 0.5$ followed by Miwa with $G=4096$ for $\rho>0.5$. For $m=6$ and $m=7$, Miwa with $G=4096$ has the best accuracy and speed followed by FORMVN with $N=12$ for $\rho \leq 0.5$ for the same accuracy level. Note that, for $m \geq 4$, TETMVN series fails to converge when $\rho>0.5$ while FORMVN series still converges but with a slower rate as $\rho$ increases. Moreover, higher accuracy can be be achieved using FORMVN by increasing $N$, but it will be at the expense of higher computational time.

TABLE 2. Average time over 50 runs for the trivariate case. Second row for each value of $\rho$ represents the standard deviation.

\begin{tabular}{c|cc|cc|c|c|cc|c}
\hline \multirow{2}{*}{} & \multicolumn{2}{|c|}{ TETMVN } & \multicolumn{2}{|c|}{ FORMVN } & \multirow{2}{*}{ SADMVN } & KROMVN & \multicolumn{2}{|c|}{ Miwa } & Plackett \\
& $N=8$ & $N=12$ & $N=8$ & $N=12$ & & & & \\
\hline 0.1 & 0.00 & 0.00 & 0.00 & 0.00 & 0.01 & 2.14 & 0.06 & 0.07 & 0.00 \\
& 0.00 & 0.00 & 0.01 & 0.01 & 0.01 & 0.92 & 0.01 & 0.02 & 0.00 \\
0.2 & 0.00 & 0.00 & 0.00 & 0.00 & 0.01 & 2.42 & 0.05 & 0.08 & 0.00 \\
& 0.00 & 0.00 & 0.00 & 0.01 & 0.01 & 1.25 & 0.01 & 0.02 & 0.00 \\
0.3 & 0.00 & 0.00 & 0.00 & 0.00 & 0.01 & 1.71 & 0.05 & 0.07 & 0.00 \\
& 0.00 & 0.00 & 0.01 & 0.01 & 0.01 & 0.85 & 0.01 & 0.02 & 0.00 \\
0.4 & 0.00 & 0.00 & 0.00 & 0.00 & 0.01 & 0.98 & 0.05 & 0.07 & 0.00 \\
& 0.00 & 0.00 & 0.01 & 0.01 & 0.01 & 0.51 & 0.01 & 0.01 & 0.00 \\
0.5 & 0.00 & 0.00 & 0.00 & 0.00 & 0.01 & 0.49 & 0.05 & 0.07 & 0.00 \\
& 0.00 & 0.00 & 0.01 & 0.01 & 0.01 & 0.41 & 0.01 & 0.02 & 0.00 \\
0.7 & 0.00 & 0.00 & 0.00 & 0.00 & 0.01 & 0.38 & 0.06 & 0.08 & 0.00 \\
& 0.00 & 0.00 & 0.01 & 0.01 & 0.01 & 0.30 & 0.01 & 0.02 & 0.00 \\
& 0.00 & 0.00 & 0.00 & 0.00 & 0.01 & 0.32 & 0.06 & 0.07 & 0.00 \\
& 0.00 & 0.00 & 0.01 & 0.01 & 0.01 & 0.26 & 0.01 & 0.01 & 0.00 \\
& 0.00 & 0.00 & 0.00 & 0.00 & 0.01 & 0.27 & 0.06 & 0.08 & 0.00 \\
& 0.00 & 0.00 & 0.01 & 0.01 & 0.01 & 0.21 & 0.01 & 0.02 & 0.00 \\
& 0.00 & 0.00 & 0.00 & 0.00 & 0.01 & 0.20 & 0.06 & 0.08 & 0.00 \\
& 0.00 & 0.00 & 0.00 & 0.01 & 0.01 & 0.20 & 0.01 & 0.02 & 0.00 \\
\hline
\end{tabular}


TABLE 3. Average absolute error over 50 runs for the trivariate case. Second row for each value of $\rho$ represents the standard deviation. ' $\mathrm{x}$ ' values in TETMVN mean that the series does not converge.

\begin{tabular}{c|cc|cc|c|c|cc|c}
\hline & \multicolumn{2}{|c|}{$T E T M V N$} & \multicolumn{2}{c|}{$F O R M V N$} & \multirow{2}{*}{ SEDMVN } & \multirow{2}{*}{ KROMVN } & \multicolumn{2}{c}{ Miwa } & Plackett \\
& $N=8$ & $N=12$ & $N=8$ & $N=12$ & & & $G=128$ & $G=4096$ & \\
\hline 0.1 & $2.10 \mathrm{E}-11$ & $1.20 \mathrm{E}-15$ & $2.20 \mathrm{E}-10$ & $6.30 \mathrm{E}-15$ & $2.10 \mathrm{E}-09$ & $6.10 \mathrm{E}-09$ & $2.40 \mathrm{E}-10$ & $8.30 \mathrm{E}-14$ & $1.30 \mathrm{E}-16$ \\
& $1.90 \mathrm{E}-11$ & $9.60 \mathrm{E}-16$ & $1.80 \mathrm{E}-10$ & $6.50 \mathrm{E}-15$ & $2.00 \mathrm{E}-10$ & $4.00 \mathrm{E}-09$ & $1.60 \mathrm{E}-10$ & $1.50 \mathrm{E}-13$ & $1.00 \mathrm{E}-16$ \\
0.2 & $6.60 \mathrm{E}-09$ & $5.10 \mathrm{E}-12$ & $1.90 \mathrm{E}-10$ & $1.30 \mathrm{E}-14$ & $1.60 \mathrm{E}-09$ & $4.80 \mathrm{E}-09$ & $2.00 \mathrm{E}-10$ & $1.40 \mathrm{E}-13$ & $1.50 \mathrm{E}-16$ \\
& $7.30 \mathrm{E}-09$ & $3.50 \mathrm{E}-12$ & $1.40 \mathrm{E}-10$ & $1.20 \mathrm{E}-14$ & $5.90 \mathrm{E}-10$ & $3.60 \mathrm{E}-09$ & $1.20 \mathrm{E}-10$ & $1.50 \mathrm{E}-13$ & $1.20 \mathrm{E}-16$ \\
0.3 & $2.20 \mathrm{E}-07$ & $1.40 \mathrm{E}-09$ & $1.50 \mathrm{E}-10$ & $1.00 \mathrm{E}-14$ & $1.20 \mathrm{E}-09$ & $3.20 \mathrm{E}-09$ & $1.10 \mathrm{E}-10$ & $2.00 \mathrm{E}-13$ & $1.00 \mathrm{E}-15$ \\
& $2.70 \mathrm{E}-07$ & $1.20 \mathrm{E}-09$ & $1.00 \mathrm{E}-10$ & $9.00 \mathrm{E}-15$ & $9.10 \mathrm{E}-10$ & $3.30 \mathrm{E}-09$ & $7.10 \mathrm{E}-11$ & $2.20 \mathrm{E}-13$ & $5.50 \mathrm{E}-16$ \\
0.4 & $2.50 \mathrm{E}-06$ & $1.30 \mathrm{E}-07$ & $1.00 \mathrm{E}-10$ & $4.90 \mathrm{E}-14$ & $1.10 \mathrm{E}-09$ & $3.50 \mathrm{E}-09$ & $7.10 \mathrm{E}-11$ & $1.80 \mathrm{E}-13$ & $5.50 \mathrm{E}-15$ \\
& $2.70 \mathrm{E}-06$ & $7.00 \mathrm{E}-08$ & $9.80 \mathrm{E}-11$ & $3.00 \mathrm{E}-14$ & $6.70 \mathrm{E}-10$ & $3.30 \mathrm{E}-09$ & $6.90 \mathrm{E}-11$ & $1.70 \mathrm{E}-13$ & $4.10 \mathrm{E}-15$ \\
0.5 & $4.10 \mathrm{E}-05$ & $1.50 \mathrm{E}-05$ & $6.50 \mathrm{E}-11$ & $7.20 \mathrm{E}-13$ & $1.40 \mathrm{E}-09$ & $4.20 \mathrm{E}-09$ & $7.20 \mathrm{E}-11$ & $2.10 \mathrm{E}-13$ & $2.00 \mathrm{E}-14$ \\
& $4.90 \mathrm{E}-05$ & $1.30 \mathrm{E}-05$ & $6.70 \mathrm{E}-11$ & $5.00 \mathrm{E}-13$ & $6.60 \mathrm{E}-10$ & $2.60 \mathrm{E}-09$ & $5.50 \mathrm{E}-11$ & $1.50 \mathrm{E}-13$ & $4.50 \mathrm{E}-14$ \\
0.6 & $1.00 \mathrm{E}-03$ & $2.30 \mathrm{E}-03$ & $1.70 \mathrm{E}-10$ & $2.00 \mathrm{E}-11$ & $2.00 \mathrm{E}-09$ & $4.00 \mathrm{E}-09$ & $1.80 \mathrm{E}-10$ & $3.70 \mathrm{E}-13$ & $3.80 \mathrm{E}-14$ \\
& $7.60 \mathrm{E}-04$ & $1.70 \mathrm{E}-03$ & $9.70 \mathrm{E}-11$ & $1.40 \mathrm{E}-11$ & $1.00 \mathrm{E}-09$ & $4.10 \mathrm{E}-09$ & $8.20 \mathrm{E}-11$ & $2.30 \mathrm{E}-13$ & $1.90 \mathrm{E}-13$ \\
0.7 & $1.10 \mathrm{E}-02$ & $2.50 \mathrm{E}-01$ & $4.20 \mathrm{E}-10$ & $8.80 \mathrm{E}-10$ & $2.30 \mathrm{E}-09$ & $4.20 \mathrm{E}-09$ & $3.80 \mathrm{E}-10$ & $3.70 \mathrm{E}-13$ & $2.50 \mathrm{E}-12$ \\
& $1.00 \mathrm{E}-02$ & $1.60 \mathrm{E}-01$ & $2.30 \mathrm{E}-10$ & $9.20 \mathrm{E}-10$ & $4.60 \mathrm{E}-09$ & $3.90 \mathrm{E}-09$ & $2.00 \mathrm{E}-10$ & $2.70 \mathrm{E}-13$ & $1.40 \mathrm{E}-11$ \\
0.8 & $\mathrm{x}$ & $\mathrm{x}$ & $8.30 \mathrm{E}-10$ & $4.40 \mathrm{E}-08$ & $1.50 \mathrm{E}-09$ & $3.30 \mathrm{E}-09$ & $1.00 \mathrm{E}-09$ & $3.70 \mathrm{E}-13$ & $6.70 \mathrm{E}-15$ \\
& $\mathrm{x}$ & $\mathrm{x}$ & $4.40 \mathrm{E}-10$ & $4.50 \mathrm{E}-08$ & $1.20 \mathrm{E}-09$ & $3.30 \mathrm{E}-09$ & $5.70 \mathrm{E}-10$ & $2.80 \mathrm{E}-13$ & $1.10 \mathrm{E}-14$ \\
0.9 & $\mathrm{x}$ & $\mathrm{x}$ & $2.60 \mathrm{E}-09$ & $5.00 \mathrm{E}-06$ & $5.00 \mathrm{E}-09$ & $2.20 \mathrm{E}-09$ & $3.20 \mathrm{E}-09$ & $4.40 \mathrm{E}-13$ & $1.80 \mathrm{E}-13$ \\
& $\mathrm{x}$ & $\mathrm{x}$ & $1.90 \mathrm{E}-09$ & $5.60 \mathrm{E}-06$ & $3.30 \mathrm{E}-09$ & $2.70 \mathrm{E}-09$ & $2.00 \mathrm{E}-09$ & $3.50 \mathrm{E}-13$ & $3.70 \mathrm{E}-13$ \\
\hline
\end{tabular}

TABLE 4. Average time over 50 runs for the quadrivariate case. Second row for each value of $\rho$ represents the standard deviation.

\begin{tabular}{c|cc|cc|c|c|cc}
\hline & \multicolumn{2}{|c|}{$T E T M V N$} & \multicolumn{2}{c|}{ FORMVN } & \multirow{2}{*}{ SADMVN } & \multirow{2}{*}{ KROMVN } & \multicolumn{2}{c}{ Miwa } \\
& $N=8$ & $N=12$ & $N=8$ & $N=12$ & & & & \\
0.1 & 0.01 & 0.05 & 0.01 & 0.03 & 0.12 & 4.69 & 0.01 & 0.10 \\
& 0.01 & 0.01 & 0.01 & 0.01 & 0.02 & 1.91 & 0.01 & 0.01 \\
0.2 & 0.01 & 0.05 & 0.01 & 0.03 & 0.13 & 6.39 & 0.00 & 0.10 \\
& 0.01 & 0.01 & 0.01 & 0.01 & 0.03 & 3.26 & 0.01 & 0.01 \\
0.3 & 0.01 & 0.05 & 0.01 & 0.03 & 0.10 & 4.64 & 0.01 & 0.10 \\
& 0.01 & 0.01 & 0.01 & 0.01 & 0.03 & 1.75 & 0.01 & 0.01 \\
0.4 & 0.01 & 0.05 & 0.01 & 0.03 & 0.07 & 3.70 & 0.01 & 0.10 \\
& 0.01 & 0.01 & 0.01 & 0.01 & 0.02 & 1.34 & 0.01 & 0.01 \\
0.5 & 0.01 & 0.05 & 0.01 & 0.03 & 0.04 & 3.12 & 0.01 & 0.10 \\
& 0.01 & 0.01 & 0.01 & 0.01 & 0.01 & 1.89 & 0.01 & 0.01 \\
0.6 & 0.01 & 0.05 & 0.01 & 0.03 & 0.03 & 2.29 & 0.00 & 0.11 \\
& 0.01 & 0.01 & 0.01 & 0.01 & 0.02 & 1.33 & 0.01 & 0.01 \\
0.7 & 0.01 & 0.05 & 0.02 & 0.03 & 0.02 & 1.78 & 0.01 & 0.11 \\
& 0.01 & 0.01 & 0.02 & 0.01 & 0.01 & 1.05 & 0.01 & 0.01 \\
0.9 & 0.01 & 0.05 & 0.02 & 0.03 & 0.02 & 1.82 & 0.01 & 0.11 \\
& 0.01 & 0.01 & 0.02 & 0.01 & 0.01 & 1.70 & 0.01 & 0.01 \\
& 0.01 & 0.06 & 0.02 & 0.03 & 0.02 & 1.54 & 0.01 & 0.11 \\
& 0.01 & 0.01 & 0.02 & 0.01 & 0.01 & 1.39 & 0.01 & 0.01 \\
\hline
\end{tabular}


TABLE 5. Average absolute error over 50 runs for the quadrivariate case. Second row for each value of $\rho$ represents the standard deviation. ' $\mathrm{x}$ ' values in TETMVN mean that the series does not converge.

\begin{tabular}{c|cc|cc|c|c|cc}
\hline & \multicolumn{2}{|c|}{$T E T M V N$} & \multicolumn{2}{c|}{ FORMVN } & \multirow{2}{*}{ SADMVN } & \multirow{2}{*}{ KROMVN } & \multicolumn{2}{c}{ Miwa } \\
& $N=8$ & $N=12$ & $N=8$ & $N=12$ & & & & \\
& $N=128$ & $G=4096$ \\
\hline 0.1 & $2.80 \mathrm{E}-11$ & $3.60 \mathrm{E}-15$ & $5.30 \mathrm{E}-10$ & $5.50 \mathrm{E}-14$ & $1.40 \mathrm{E}-08$ & $3.60 \mathrm{E}-09$ & $1.60 \mathrm{E}-09$ & $4.10 \mathrm{E}-13$ \\
& $2.90 \mathrm{E}-11$ & $2.90 \mathrm{E}-15$ & $4.30 \mathrm{E}-10$ & $9.10 \mathrm{E}-14$ & $5.40 \mathrm{E}-09$ & $2.90 \mathrm{E}-09$ & $6.20 \mathrm{E}-10$ & $4.50 \mathrm{E}-13$ \\
0.2 & $6.10 \mathrm{E}-09$ & $4.10 \mathrm{E}-12$ & $1.00 \mathrm{E}-09$ & $4.50 \mathrm{E}-14$ & $1.40 \mathrm{E}-08$ & $3.50 \mathrm{E}-09$ & $1.30 \mathrm{E}-09$ & $5.30 \mathrm{E}-13$ \\
& $4.30 \mathrm{E}-09$ & $3.70 \mathrm{E}-12$ & $7.30 \mathrm{E}-10$ & $4.60 \mathrm{E}-14$ & $5.00 \mathrm{E}-09$ & $2.50 \mathrm{E}-09$ & $5.10 \mathrm{E}-10$ & $4.30 \mathrm{E}-13$ \\
0.3 & $2.00 \mathrm{E}-07$ & $2.10 \mathrm{E}-09$ & $2.20 \mathrm{E}-09$ & $5.90 \mathrm{E}-14$ & $6.10 \mathrm{E}-09$ & $1.80 \mathrm{E}-09$ & $1.10 \mathrm{E}-09$ & $7.50 \mathrm{E}-13$ \\
& $1.70 \mathrm{E}-07$ & $2.30 \mathrm{E}-09$ & $1.70 \mathrm{E}-09$ & $5.80 \mathrm{E}-14$ & $2.10 \mathrm{E}-09$ & $2.00 \mathrm{E}-09$ & $4.20 \mathrm{E}-10$ & $6.10 \mathrm{E}-13$ \\
0.4 & $1.20 \mathrm{E}-05$ & $1.40 \mathrm{E}-04$ & $4.50 \mathrm{E}-09$ & $6.60 \mathrm{E}-14$ & $2.80 \mathrm{E}-09$ & $2.40 \mathrm{E}-09$ & $6.80 \mathrm{E}-10$ & $8.20 \mathrm{E}-13$ \\
& $9.50 \mathrm{E}-06$ & $1.10 \mathrm{E}-04$ & $3.40 \mathrm{E}-09$ & $6.20 \mathrm{E}-14$ & $1.40 \mathrm{E}-09$ & $2.10 \mathrm{E}-09$ & $3.00 \mathrm{E}-10$ & $5.70 \mathrm{E}-13$ \\
0.5 & $4.80 \mathrm{E}-02$ & $\mathrm{x}$ & $3.00 \mathrm{E}-08$ & $1.40 \mathrm{E}-12$ & $1.80 \mathrm{E}-09$ & $2.80 \mathrm{E}-09$ & $6.10 \mathrm{E}-10$ & $8.80 \mathrm{E}-13$ \\
& $3.40 \mathrm{E}-02$ & $\mathrm{x}$ & $2.20 \mathrm{E}-08$ & $1.20 \mathrm{E}-12$ & $1.30 \mathrm{E}-09$ & $2.70 \mathrm{E}-09$ & $3.60 \mathrm{E}-10$ & $5.90 \mathrm{E}-13$ \\
0.6 & $\mathrm{x}$ & $\mathrm{x}$ & $1.60 \mathrm{E}-07$ & $3.50 \mathrm{E}-11$ & $4.50 \mathrm{E}-09$ & $2.60 \mathrm{E}-09$ & $4.50 \mathrm{E}-10$ & $1.40 \mathrm{E}-12$ \\
& $\mathrm{x}$ & $\mathrm{x}$ & $1.10 \mathrm{E}-07$ & $2.20 \mathrm{E}-11$ & $3.20 \mathrm{E}-09$ & $2.00 \mathrm{E}-09$ & $2.80 \mathrm{E}-10$ & $6.70 \mathrm{E}-13$ \\
0.7 & $\mathrm{x}$ & $\mathrm{x}$ & $1.20 \mathrm{E}-06$ & $1.40 \mathrm{E}-09$ & $2.80 \mathrm{E}-09$ & $2.00 \mathrm{E}-09$ & $4.00 \mathrm{E}-10$ & $1.10 \mathrm{E}-12$ \\
& $\mathrm{x}$ & $\mathrm{x}$ & $9.00 \mathrm{E}-07$ & $1.10 \mathrm{E}-09$ & $1.80 \mathrm{E}-09$ & $1.70 \mathrm{E}-09$ & $2.10 \mathrm{E}-10$ & $5.30 \mathrm{E}-13$ \\
0.8 & $\mathrm{x}$ & $\mathrm{x}$ & $1.20 \mathrm{E}-05$ & $9.70 \mathrm{E}-08$ & $5.60 \mathrm{E}-09$ & $2.80 \mathrm{E}-09$ & $8.60 \mathrm{E}-10$ & $1.80 \mathrm{E}-12$ \\
& $\mathrm{x}$ & $\mathrm{x}$ & $8.90 \mathrm{E}-06$ & $8.40 \mathrm{E}-08$ & $4.90 \mathrm{E}-09$ & $2.60 \mathrm{E}-09$ & $5.20 \mathrm{E}-10$ & $2.00 \mathrm{E}-12$ \\
0.9 & $\mathrm{x}$ & $\mathrm{x}$ & $1.50 \mathrm{E}-04$ & $9.40 \mathrm{E}-06$ & $5.90 \mathrm{E}-09$ & $2.30 \mathrm{E}-09$ & $1.90 \mathrm{E}-09$ & $2.10 \mathrm{E}-12$ \\
& $\mathrm{x}$ & $\mathrm{x}$ & $1.20 \mathrm{E}-04$ & $6.70 \mathrm{E}-06$ & $4.00 \mathrm{E}-09$ & $2.30 \mathrm{E}-09$ & $1.50 \mathrm{E}-09$ & $4.00 \mathrm{E}-12$ \\
\hline
\end{tabular}

TABle 6. Average time over 50 runs for the 5 -variate case. Second row for each value of $\rho$ represents the standard deviation.

\begin{tabular}{c|cc|cc|c|c|cc}
\hline \multirow{4}{*}{} & \multicolumn{2}{|c|}{ TETMVN } & \multicolumn{2}{c|}{ FORMVN } & \multirow{2}{*}{ SADMVN } & \multirow{2}{*}{ KROMVN } & \multicolumn{2}{c}{ Miwa } \\
& $N=8$ & $N=12$ & $N=8$ & $N=12$ & & & & \\
\hline \multirow{5}{*}{0.1} & 23.46 & - & 0.08 & 0.26 & 55.49 & 7.55 & 0.02 & 0.52 \\
& 0.75 & - & 0.01 & 0.01 & 48.27 & 2.90 & 0.00 & 0.05 \\
& 23.99 & - & 0.08 & 0.27 & 35.76 & 12.32 & 0.02 & 0.52 \\
& 0.94 & - & 0.01 & 0.01 & 37.74 & 9.21 & 0.00 & 0.04 \\
0.3 & 24.29 & - & 0.08 & 0.28 & 32.33 & 16.72 & 0.02 & 0.51 \\
& 0.95 & - & 0.01 & 0.01 & 38.36 & 15.26 & 0.00 & 0.03 \\
0.4 & 25.12 & - & 0.08 & 0.29 & 11.01 & 15.86 & 0.02 & 0.52 \\
& 0.54 & - & 0.01 & 0.01 & 21.59 & 21.93 & 0.01 & 0.02 \\
0.5 & 25.00 & - & 0.08 & 0.32 & 1.44 & 10.35 & 0.02 & 0.52 \\
& 0.32 & - & 0.01 & 0.01 & 1.38 & 13.46 & 0.00 & 0.02 \\
0.6 & 25.05 & - & 0.09 & 0.37 & 1.90 & 8.20 & 0.02 & 0.53 \\
& 0.45 & - & 0.01 & 0.01 & 6.05 & 10.11 & 0.01 & 0.03 \\
0.7 & 25.02 & - & 0.09 & 0.41 & 0.35 & 8.65 & 0.02 & 0.53 \\
& 0.18 & - & 0.01 & 0.01 & 0.44 & 12.67 & 0.01 & 0.02 \\
0.8 & 25.12 & - & 0.09 & 0.46 & 0.16 & 6.84 & 0.02 & 0.55 \\
& 0.48 & - & 0.01 & 0.01 & 0.22 & 10.10 & 0.00 & 0.02 \\
0.9 & 24.96 & - & 0.09 & 0.50 & 0.08 & 3.23 & 0.02 & 0.54 \\
& 0.37 & - & 0.01 & 0.02 & 0.16 & 3.31 & 0.00 & 0.02 \\
\hline
\end{tabular}


TABLE 7. Average absolute error over 50 runs for the 5 -variate case. Second row for each value of $\rho$ represents the standard deviation. ' $\mathrm{x}$ ' values in TETMVN mean that the series does not converge. '-' values mean that the algorithm takes more than 200 sec.

\begin{tabular}{c|cc|cc|c|c|cc}
\hline \multirow{2}{*}{} & \multicolumn{2}{|c|}{ TETMVN } & \multicolumn{2}{c|}{ FORMVN } & \multirow{2}{*}{ SADMN } & \multirow{2}{*}{ KROMVN } & \multicolumn{2}{c}{ Miwa } \\
& $N=8$ & $N=12$ & $N=8$ & $N=12$ & & & & \\
\hline 0.1 & $2.60 \mathrm{E}-11$ & - & $5.90 \mathrm{E}-10$ & $4.80 \mathrm{E}-13$ & $1.00 \mathrm{E}-07$ & $5.20 \mathrm{E}-09$ & $3.60 \mathrm{E}-09$ & $7.90 \mathrm{E}-13$ \\
& $1.90 \mathrm{E}-11$ & - & $5.60 \mathrm{E}-10$ & $8.00 \mathrm{E}-13$ & $3.50 \mathrm{E}-08$ & $6.10 \mathrm{E}-09$ & $1.00 \mathrm{E}-09$ & $7.80 \mathrm{E}-13$ \\
0.2 & $7.10 \mathrm{E}-09$ & - & $1.10 \mathrm{E}-09$ & $2.30 \mathrm{E}-13$ & $9.10 \mathrm{E}-08$ & $3.40 \mathrm{E}-09$ & $3.00 \mathrm{E}-09$ & $1.30 \mathrm{E}-12$ \\
0.3 & $5.30 \mathrm{E}-09$ & - & $8.60 \mathrm{E}-10$ & $2.10 \mathrm{E}-13$ & $3.90 \mathrm{E}-08$ & $2.90 \mathrm{E}-09$ & $1.10 \mathrm{E}-09$ & $1.30 \mathrm{E}-12$ \\
& $2.80 \mathrm{E}-07$ & - & $3.00 \mathrm{E}-09$ & $2.40 \mathrm{E}-13$ & $7.50 \mathrm{E}-08$ & $4.40 \mathrm{E}-09$ & $2.60 \mathrm{E}-09$ & $1.20 \mathrm{E}-12$ \\
0.4 & $2.30 \mathrm{E}-07$ & - & $1.90 \mathrm{E}-09$ & $2.60 \mathrm{E}-13$ & $2.90 \mathrm{E}-08$ & $3.90 \mathrm{E}-09$ & $1.00 \mathrm{E}-09$ & $9.40 \mathrm{E}-13$ \\
0.5 & $\mathrm{x}$ & - & $1.10 \mathrm{E}-08$ & $2.80 \mathrm{E}-13$ & $6.20 \mathrm{E}-08$ & $2.90 \mathrm{E}-09$ & $2.10 \mathrm{E}-09$ & $2.20 \mathrm{E}-12$ \\
& $\mathrm{x}$ & - & $6.50 \mathrm{E}-09$ & $2.10 \mathrm{E}-13$ & $3.30 \mathrm{E}-08$ & $2.10 \mathrm{E}-09$ & $9.30 \mathrm{E}-10$ & $1.50 \mathrm{E}-12$ \\
0.6 & $\mathrm{x}$ & - & $3.70 \mathrm{E}-08$ & $2.30 \mathrm{E}-12$ & $3.50 \mathrm{E}-08$ & $2.40 \mathrm{E}-09$ & $1.70 \mathrm{E}-09$ & $2.20 \mathrm{E}-12$ \\
& $\mathrm{x}$ & - & $3.40 \mathrm{E}-08$ & $2.00 \mathrm{E}-12$ & $1.80 \mathrm{E}-08$ & $2.10 \mathrm{E}-09$ & $8.60 \mathrm{E}-10$ & $1.40 \mathrm{E}-12$ \\
0.7 & $\mathrm{x}$ & - & $2.00 \mathrm{E}-07$ & $5.50 \mathrm{E}-11$ & $2.10 \mathrm{E}-08$ & $3.20 \mathrm{E}-09$ & $1.00 \mathrm{E}-09$ & $2.40 \mathrm{E}-12$ \\
& $\mathrm{x}$ & - & $1.40 \mathrm{E}-07$ & $3.50 \mathrm{E}-11$ & $2.10 \mathrm{E}-08$ & $3.00 \mathrm{E}-09$ & $8.40 \mathrm{E}-10$ & $1.30 \mathrm{E}-12$ \\
0.8 & $\mathrm{x}$ & - & $1.70 \mathrm{E}-06$ & $2.00 \mathrm{E}-09$ & $1.40 \mathrm{E}-08$ & $3.20 \mathrm{E}-09$ & $9.80 \mathrm{E}-10$ & $3.00 \mathrm{E}-12$ \\
& $\mathrm{x}$ & - & $1.20 \mathrm{E}-06$ & $1.80 \mathrm{E}-09$ & $1.30 \mathrm{E}-08$ & $3.10 \mathrm{E}-09$ & $8.90 \mathrm{E}-10$ & $1.50 \mathrm{E}-12$ \\
0.9 & $\mathrm{x}$ & - & $1.50 \mathrm{E}-05$ & $1.60 \mathrm{E}-07$ & $6.60 \mathrm{E}-09$ & $2.80 \mathrm{E}-09$ & $1.10 \mathrm{E}-09$ & $2.80 \mathrm{E}-12$ \\
& $\mathrm{x}$ & - & $1.30 \mathrm{E}-05$ & $1.20 \mathrm{E}-07$ & $5.70 \mathrm{E}-09$ & $2.90 \mathrm{E}-09$ & $6.90 \mathrm{E}-10$ & $1.90 \mathrm{E}-12$ \\
& $\mathrm{x}$ & - & $1.80 \mathrm{E}-04$ & $9.10 \mathrm{E}-06$ & $8.70 \mathrm{E}-09$ & $3.30 \mathrm{E}-09$ & $2.40 \mathrm{E}-09$ & $2.80 \mathrm{E}-12$ \\
& $\mathrm{x}$ & - & $1.40 \mathrm{E}-04$ & $7.40 \mathrm{E}-06$ & $6.50 \mathrm{E}-09$ & $3.50 \mathrm{E}-09$ & $2.10 \mathrm{E}-09$ & $1.90 \mathrm{E}-12$ \\
\hline
\end{tabular}

TABle 8. Average time over 50 runs for the 6 -variate case. Second row for each value of $\rho$ represents the standard deviation.

\begin{tabular}{|c|c|c|c|c|c|c|c|c|}
\hline & \multicolumn{2}{|c|}{$T E T M V N$} & \multicolumn{2}{|c|}{ FORMVN } & \multirow{2}{*}{$S A D M V N$} & \multirow{2}{*}{ KROMVN } & \multicolumn{2}{|c|}{ Miwa } \\
\hline & $N=8$ & $N=12$ & $N=8$ & $N=12$ & & & $G=128$ & $G=4096$ \\
\hline \multirow[t]{2}{*}{0.1} & - & - & 0.88 & 4.93 & 130.15 & 21.40 & 0.10 & 3.38 \\
\hline & - & - & 0.01 & 0.03 & 23.06 & 12.04 & 0.01 & 0.21 \\
\hline \multirow[t]{2}{*}{0.2} & - & - & 0.91 & 5.09 & 122.98 & 51.49 & 0.10 & 3.32 \\
\hline & - & - & 0.01 & 0.06 & 31.09 & 38.78 & 0.01 & 0.17 \\
\hline \multirow[t]{2}{*}{0.3} & - & - & 0.96 & 5.23 & 119.60 & 45.97 & 0.11 & 3.24 \\
\hline & - & - & 0.02 & 0.04 & 35.34 & 42.72 & 0.01 & 0.17 \\
\hline \multirow[t]{2}{*}{0.4} & - & - & 1.04 & 5.42 & 108.55 & 49.44 & 0.10 & 3.30 \\
\hline & - & - & 0.01 & 0.04 & 49.35 & 46.49 & 0.01 & 0.13 \\
\hline \multirow[t]{2}{*}{0.5} & - & - & 1.14 & 5.69 & 58.59 & 50.97 & 0.10 & 3.34 \\
\hline & - & - & 0.02 & 0.03 & 58.30 & 51.55 & 0.01 & 0.11 \\
\hline \multirow[t]{2}{*}{0.6} & - & - & 1.29 & 6.28 & 38.87 & 54.76 & 0.10 & 3.40 \\
\hline & - & - & 0.10 & 0.15 & 51.63 & 51.53 & 0.01 & 0.13 \\
\hline \multirow[t]{2}{*}{0.7} & - & - & 1.41 & 7.04 & 14.59 & 34.60 & 0.11 & 3.43 \\
\hline & - & - & 0.02 & 0.05 & 33.58 & 44.23 & 0.01 & 0.10 \\
\hline \multirow[t]{2}{*}{0.8} & - & - & 1.54 & 8.35 & 3.27 & 16.73 & 0.11 & 3.43 \\
\hline & - & - & 0.08 & 0.07 & 9.84 & 30.09 & 0.01 & 0.10 \\
\hline \multirow[t]{2}{*}{0.9} & - & - & 1.58 & 9.83 & 0.45 & 10.21 & 0.11 & 3.38 \\
\hline & - & - & 0.02 & 0.11 & 1.17 & 19.11 & 0.01 & 0.14 \\
\hline
\end{tabular}


TABLE 9. Average absolute error over 50 runs for the 6 -variate case. Second row for each value of $\rho$ represents the standard deviation. '-' values mean that the algorithm takes more than 200 sec.

\begin{tabular}{c|cc|cc|c|c|cc}
\hline & \multicolumn{2}{|c|}{ TETMVN } & \multicolumn{2}{c|}{ FORMVN } & \multirow{2}{*}{ SADMVN } & \multirow{2}{*}{ KROMVN } & \multicolumn{2}{c}{ Miwa } \\
& $N=8$ & $N=12$ & $N=8$ & $N=12$ & & & & \\
\hline 0.1 & - & - & $6.60 \mathrm{E}-10$ & $1.10 \mathrm{E}-12$ & $7.20 \mathrm{E}-07$ & $3.70 \mathrm{E}-09$ & $3.30 \mathrm{E}-09$ & $1.50 \mathrm{E}-12$ \\
0.2 & - & - & $5.10 \mathrm{E}-10$ & $1.20 \mathrm{E}-12$ & $7.60 \mathrm{E}-07$ & $3.10 \mathrm{E}-09$ & $1.40 \mathrm{E}-09$ & $1.20 \mathrm{E}-12$ \\
& - & - & $1.30 \mathrm{E}-09$ & $1.10 \mathrm{E}-12$ & $8.90 \mathrm{E}-07$ & $3.40 \mathrm{E}-09$ & $2.50 \mathrm{E}-09$ & $1.80 \mathrm{E}-12$ \\
0.3 & - & - & $8.40 \mathrm{E}-10$ & $1.70 \mathrm{E}-12$ & $6.50 \mathrm{E}-07$ & $2.90 \mathrm{E}-09$ & $1.20 \mathrm{E}-09$ & $1.30 \mathrm{E}-12$ \\
& - & - & $2.40 \mathrm{E}-09$ & $2.50 \mathrm{E}-12$ & $4.60 \mathrm{E}-07$ & $2.80 \mathrm{E}-09$ & $1.90 \mathrm{E}-09$ & $2.50 \mathrm{E}-12$ \\
0.4 & - & - & $1.80 \mathrm{E}-09$ & $2.70 \mathrm{E}-12$ & $3.80 \mathrm{E}-07$ & $2.60 \mathrm{E}-09$ & $1.30 \mathrm{E}-09$ & $1.90 \mathrm{E}-12$ \\
& - & - & $7.90 \mathrm{E}-09$ & $1.40 \mathrm{E}-12$ & $2.90 \mathrm{E}-07$ & $2.70 \mathrm{E}-09$ & $2.10 \mathrm{E}-09$ & $3.40 \mathrm{E}-12$ \\
0.5 & - & - & $6.20 \mathrm{E}-09$ & $1.90 \mathrm{E}-12$ & $2.20 \mathrm{E}-07$ & $2.70 \mathrm{E}-09$ & $1.20 \mathrm{E}-09$ & $2.30 \mathrm{E}-12$ \\
& - & - & $5.80 \mathrm{E}-08$ & $3.00 \mathrm{E}-12$ & $1.70 \mathrm{E}-07$ & $3.20 \mathrm{E}-09$ & $1.70 \mathrm{E}-09$ & $5.00 \mathrm{E}-12$ \\
0.6 & - & - & $3.30 \mathrm{E}-08$ & $2.10 \mathrm{E}-12$ & $2.00 \mathrm{E}-07$ & $4.30 \mathrm{E}-09$ & $1.60 \mathrm{E}-09$ & $3.60 \mathrm{E}-12$ \\
& - & - & $2.50 \mathrm{E}-07$ & $6.60 \mathrm{E}-11$ & $9.30 \mathrm{E}-08$ & $3.40 \mathrm{E}-09$ & $1.60 \mathrm{E}-09$ & $4.80 \mathrm{E}-12$ \\
0.7 & - & - & $2.00 \mathrm{E}-07$ & $5.90 \mathrm{E}-11$ & $7.60 \mathrm{E}-08$ & $2.70 \mathrm{E}-09$ & $1.50 \mathrm{E}-09$ & $2.20 \mathrm{E}-12$ \\
& - & - & $1.80 \mathrm{E}-06$ & $3.10 \mathrm{E}-09$ & $5.00 \mathrm{E}-08$ & $3.90 \mathrm{E}-09$ & $1.50 \mathrm{E}-09$ & $6.40 \mathrm{E}-12$ \\
0.8 & - & - & $1.30 \mathrm{E}-06$ & $3.80 \mathrm{E}-09$ & $5.70 \mathrm{E}-08$ & $3.60 \mathrm{E}-09$ & $1.50 \mathrm{E}-09$ & $4.30 \mathrm{E}-12$ \\
& - & - & $1.50 \mathrm{E}-05$ & $2.10 \mathrm{E}-07$ & $2.70 \mathrm{E}-08$ & $3.90 \mathrm{E}-09$ & $1.50 \mathrm{E}-09$ & $7.10 \mathrm{E}-12$ \\
0.9 & - & - & $1.20 \mathrm{E}-05$ & $2.00 \mathrm{E}-07$ & $2.00 \mathrm{E}-08$ & $3.10 \mathrm{E}-09$ & $1.50 \mathrm{E}-09$ & $7.40 \mathrm{E}-12$ \\
& - & - & $2.20 \mathrm{E}-04$ & $1.50 \mathrm{E}-05$ & $1.50 \mathrm{E}-08$ & $3.90 \mathrm{E}-09$ & $1.90 \mathrm{E}-09$ & $6.90 \mathrm{E}-12$ \\
& - & - & $1.80 \mathrm{E}-04$ & $1.30 \mathrm{E}-05$ & $1.00 \mathrm{E}-08$ & $3.50 \mathrm{E}-09$ & $1.90 \mathrm{E}-09$ & $6.00 \mathrm{E}-12$ \\
\hline
\end{tabular}

TABle 10. Average time over 50 runs for the 7 -variate case. Second row for each value of $\rho$ represents the standard deviation.

\begin{tabular}{|c|c|c|c|c|c|c|c|c|}
\hline & \multicolumn{2}{|c|}{$T E T M V N$} & \multicolumn{2}{|c|}{ FORMVN } & \multirow{2}{*}{$S A D M V N$} & \multirow{2}{*}{ KROMVN } & \multicolumn{2}{|c|}{ Miwa } \\
\hline & $N=8$ & $N=12$ & $N=8$ & $N=12$ & & & $G=128$ & $G=4096$ \\
\hline \multirow[t]{2}{*}{0.1} & - & - & 9.49 & 107.49 & 153.55 & 136.06 & 0.94 & 31.33 \\
\hline & - & - & 0.05 & 0.63 & 20.64 & 51.14 & 0.04 & 1.27 \\
\hline \multirow[t]{2}{*}{0.2} & - & - & 9.89 & 108.32 & 149.16 & 168.21 & 0.94 & 31.09 \\
\hline & - & - & 0.11 & 0.31 & 19.24 & 0.93 & 0.04 & 1.47 \\
\hline \multirow[t]{2}{*}{0.3} & - & - & 10.41 & 109.74 & 149.12 & 168.25 & 0.94 & 30.15 \\
\hline & - & - & 0.08 & 0.69 & 19.36 & 10.53 & 0.03 & 1.11 \\
\hline \multirow[t]{2}{*}{0.4} & - & - & 11.19 & 111.81 & 144.85 & 167.63 & 0.95 & 30.51 \\
\hline & - & - & 0.17 & 0.72 & 24.58 & 20.43 & 0.03 & 0.86 \\
\hline \multirow[t]{2}{*}{0.5} & - & - & 12.31 & 116.41 & 116.68 & 169.81 & 0.96 & 30.52 \\
\hline & - & - & 0.28 & 2.71 & 59.34 & 41.80 & 0.03 & 0.86 \\
\hline \multirow[t]{2}{*}{0.6} & - & - & 13.88 & 120.67 & 84.07 & 163.86 & 1.00 & 32.94 \\
\hline & - & - & 0.17 & 1.54 & 63.04 & 34.83 & 0.07 & 2.16 \\
\hline \multirow[t]{2}{*}{0.7} & - & - & 16.48 & 131.77 & 35.82 & 124.93 & 1.03 & 32.57 \\
\hline & - & - & 2.06 & 0.42 & 52.86 & 66.73 & 0.07 & 2.33 \\
\hline \multirow[t]{2}{*}{0.8} & - & - & 18.18 & 154.93 & 15.00 & 91.25 & 1.01 & 31.25 \\
\hline & - & - & 0.59 & 0.85 & 35.28 & 75.91 & 0.05 & 0.95 \\
\hline \multirow[t]{2}{*}{0.9} & - & - & 18.85 & 198.17 & 3.89 & 44.31 & 1.00 & 30.73 \\
\hline & - & - & 0.14 & 1.84 & 23.10 & 71.90 & 0.04 & 1.05 \\
\hline
\end{tabular}


TABLE 11. Average absolute error over 50 runs for the 7 -variate case. Second row for each value of $\rho$ represents the standard deviation. '-' values mean that the algorithm takes more than 200 sec.

\begin{tabular}{c|cc|cc|c|c|cc}
\hline & \multicolumn{2}{|c|}{ TETMVN } & \multicolumn{2}{|c|}{ FORMVN } & \multirow{2}{*}{ SADMVN } & \multirow{2}{*}{ KROMVN } & \multicolumn{2}{c}{ Miwa } \\
& $N=8$ & $N=12$ & $N=8$ & $N=12$ & & & $G=128$ & $G=4096$ \\
\hline 0.1 & - & - & $8.70 \mathrm{E}-10$ & $2.60 \mathrm{E}-12$ & $1.40 \mathrm{E}-06$ & $6.20 \mathrm{E}-09$ & $2.60 \mathrm{E}-09$ & $2.90 \mathrm{E}-12$ \\
& - & - & $5.30 \mathrm{E}-10$ & $1.90 \mathrm{E}-12$ & $1.10 \mathrm{E}-06$ & $5.90 \mathrm{E}-09$ & $2.40 \mathrm{E}-09$ & $2.20 \mathrm{E}-12$ \\
0.2 & - & - & $1.10 \mathrm{E}-09$ & $6.80 \mathrm{E}-12$ & $2.40 \mathrm{E}-06$ & $1.20 \mathrm{E}-08$ & $3.20 \mathrm{E}-09$ & $3.90 \mathrm{E}-12$ \\
& - & - & $7.70 \mathrm{E}-10$ & $1.10 \mathrm{E}-11$ & $2.30 \mathrm{E}-06$ & $1.00 \mathrm{E}-08$ & $2.30 \mathrm{E}-09$ & $2.00 \mathrm{E}-12$ \\
0.3 & - & - & $3.10 \mathrm{E}-09$ & $5.30 \mathrm{E}-12$ & $1.60 \mathrm{E}-06$ & $1.20 \mathrm{E}-08$ & $3.40 \mathrm{E}-09$ & $5.00 \mathrm{E}-12$ \\
& - & - & $2.70 \mathrm{E}-09$ & $4.70 \mathrm{E}-12$ & $1.20 \mathrm{E}-06$ & $1.40 \mathrm{E}-08$ & $1.90 \mathrm{E}-09$ & $6.30 \mathrm{E}-12$ \\
0.4 & - & - & $1.10 \mathrm{E}-08$ & $1.30 \mathrm{E}-11$ & $1.40 \mathrm{E}-06$ & $1.60 \mathrm{E}-08$ & $3.00 \mathrm{E}-09$ & $6.30 \mathrm{E}-12$ \\
& - & - & $1.00 \mathrm{E}-08$ & $1.50 \mathrm{E}-11$ & $1.10 \mathrm{E}-06$ & $1.50 \mathrm{E}-08$ & $1.60 \mathrm{E}-09$ & $5.00 \mathrm{E}-12$ \\
0.5 & - & - & $4.50 \mathrm{E}-08$ & $1.60 \mathrm{E}-11$ & $5.50 \mathrm{E}-07$ & $1.40 \mathrm{E}-08$ & $2.40 \mathrm{E}-09$ & $9.00 \mathrm{E}-12$ \\
0.6 & - & - & $3.30 \mathrm{E}-08$ & $1.90 \mathrm{E}-11$ & $5.00 \mathrm{E}-07$ & $1.90 \mathrm{E}-08$ & $1.70 \mathrm{E}-09$ & $9.40 \mathrm{E}-12$ \\
0.7 & - & - & $3.80 \mathrm{E}-07$ & $1.10 \mathrm{E}-10$ & $2.90 \mathrm{E}-07$ & $1.30 \mathrm{E}-08$ & $2.40 \mathrm{E}-09$ & $9.80 \mathrm{E}-12$ \\
& - & - & $3.70 \mathrm{E}-07$ & $1.10 \mathrm{E}-10$ & $4.50 \mathrm{E}-07$ & $1.50 \mathrm{E}-08$ & $2.60 \mathrm{E}-09$ & $5.90 \mathrm{E}-12$ \\
0.8 & - & - & $2.20 \mathrm{E}-06$ & $4.10 \mathrm{E}-09$ & $1.20 \mathrm{E}-07$ & $8.70 \mathrm{E}-09$ & $2.20 \mathrm{E}-09$ & $1.00 \mathrm{E}-11$ \\
& - & - & $1.60 \mathrm{E}-06$ & $3.10 \mathrm{E}-09$ & $1.40 \mathrm{E}-07$ & $9.10 \mathrm{E}-09$ & $1.80 \mathrm{E}-09$ & $7.80 \mathrm{E}-12$ \\
0.9 & - & - & $2.20 \mathrm{E}-05$ & $2.50 \mathrm{E}-07$ & $5.00 \mathrm{E}-08$ & $5.40 \mathrm{E}-09$ & $2.10 \mathrm{E}-09$ & $1.30 \mathrm{E}-11$ \\
& - & - & $1.90 \mathrm{E}-05$ & $2.30 \mathrm{E}-07$ & $4.70 \mathrm{E}-08$ & $6.70 \mathrm{E}-09$ & $2.00 \mathrm{E}-09$ & $8.70 \mathrm{E}-12$ \\
& - & - & $2.30 \mathrm{E}-04$ & $2.00 \mathrm{E}-05$ & $2.30 \mathrm{E}-08$ & $5.90 \mathrm{E}-09$ & $1.50 \mathrm{E}-09$ & $1.30 \mathrm{E}-11$ \\
& - & $2.10 \mathrm{E}-04$ & $1.80 \mathrm{E}-05$ & $2.30 \mathrm{E}-08$ & $1.50 \mathrm{E}-08$ & $1.30 \mathrm{E}-09$ & $1.60 \mathrm{E}-11$ \\
\hline
\end{tabular}

\section{Conclusions}

In this article, we expressed the multivariate normal probability integral using Fourier series expansion. This expansion is found to converge rapidly for small values of the correlation coefficients compared to the well-known tetrachoric series and it is better than Miwa's method for $m=3$ to $m=5$ when $\rho \leq 0.5$ and outperforms $S A D M V N$ and $K R O M V N$ especially for $\rho \leq 0.5$. Moreover, another series expansion is derived for the bivariate case that converges fast for all values of $\rho$.

\section{RefERENCES}

[1] M. Abramowitz, I.A. Stegun, Handbook of Mathematical Functions, Dover, New York, 1964.

[2] I. Deák, Three digit accurate multiple normal probabilities, Numer. Math. 35 (1980), no. 4, 369-380, DOI 10.1007/BF01399006. MR.593834 (83a:65008)

[3] István Deák, Random number generators and simulation, Mathematical Methods of Operations Research, vol. 4, Akadémiai Kiadó (Publishing House of the Hungarian Academy of Sciences), Budapest, 1990. Translated and revised from the Hungarian by the author. MR 1080965 (92f:65014)

[4] D. R. Divgi, Calculation of univariate and bivariate normal probability functions, Ann. Statist. 7 (1979), no. 4, 903-910. MR.532253 (80d:62021)

[5] T.G. Donnelly, Algorithm 462: Bivariate normal distribution, Commun. ACM 16 (1973) 636.

[6] Z. Drezner, Computation of the bivariate normal integral, Math. Comp. 32 (1978), no. 141, 277-279. MR0461849 (57 \#1833)

[7] Zvi Drezner and G. O. Wesolowsky, On the computation of the bivariate normal integral, J. Statist. Comput. Simulation 35 (1990), no. 1-2, 101-107, DOI 10.1080/00949659008811236. MR 1041725 
[8] H. Fayed, A. Atiya, An evaluation of the integral of the product of the error function and the normal probability density, with application to the bivariate normal integral, Math. Comp. 83 (2014), 235-250. MR.3120588

[9] J. Gai, A computational study of the bivariate normal probability function, M.Sc. thesis, Department of Mathematics and Statistics, Queen's University, Kingston, Ontario, Canada, 2002.

[10] H. I. Gassmann, Multivariate normal probabilities: implementing an old idea of Plackett's, J. Comput. Graph. Statist. 12 (2003), no. 3, 731-752, DOI 10.1198/1061860032283. MR2005459

[11] A. Genz, Numerical computation of multivariate normal probabilities, J. Comp. Graph. Stat. 1 (1992) 141-150.

[12] A. Genz, Comparison of methods for the computation of multivariate normal probabilities, Comp. Sci. Stat. 25 (1993) 400-405.

[13] Alan Genz, Numerical computation of rectangular bivariate and trivariate normal and $t$ probabilities, Stat. Comput. 14 (2004), no. 3, 251-260, DOI 10.1023/B:STCO.0000035304.20635.31. MR2086401

[14] Alan Genz and Frank Bretz, Computation of multivariate normal and t probabilities, Lecture Notes in Statistics, vol. 195, Springer, Dordrecht, 2009. MR2840595 (2012f:60002)

[15] Shanti S. Gupta, Probability integrals of multivariate normal and multivariate $t$, Ann. Math. Statist. 34 (1963), 792-828. MR0152068 (27 \#2048)

[16] Bernard Harris and Andrew P. Soms, The use of the tetrachoric series for evaluating multivariate normal probabilities, J. Multivariate Anal. 10 (1980), no. 2, 252-267, DOI 10.1016/0047-259X(80)90017-2. MR.575928 (81h:62117)

[17] N.L. Johnson, S. Kotz, Distributions in statistics: Continuous multivariate distribution, John Wiley and Sons, New York, 1972.

[18] M. G. Kendall, Proof of relations connected with the tetrachoric series and its generalization, Biometrika 32 (1941), 196-198. MR0005573(3,173f)

[19] Tetsuhisa Miwa, A. J. Hayter, and Satoshi Kuriki, The evaluation of general non-centred orthant probabilities, J. R. Stat. Soc. Ser. B Stat. Methodol. 65 (2003), no. 1, 223-234, DOI 10.1111/1467-9868.00382. MR.1959823 (2003m:62045)

[20] Donald B. Owen, Tables for computing bivariate normal probabilities, Ann. Math. Statist. 27 (1956), 1075-1090. MR0127562 (23 \#B607)

[21] K. Pearson, Mathematical contributions to the theory of evolution. VII. on the correlation of characters not quantitatively. Philos. Trans. R. Soc. S-A. 196 (1901) 1-47.

[22] A. P. Prudnikov, Yu. A. Brychkov, and O. I. Marichev, Integrals and series. Vol. 1, Gordon \& Breach Science Publishers, New York, 1986. Elementary functions; Translated from the Russian and with a preface by N. M. Queen. MR874986 (88f:00013)

[23] N. G. Shephard, From characteristic function to distribution function: a simple framework for the theory, Econometric Theory 7 (1991), no. 4, 519-529, DOI 10.1017/S0266466600004746. MR:1151944 (94b:60026)

[24] Tamás Szántai, An algorithm for determining the values of multivariate normal distributions and their gradients (Hungarian, with English summary), Alkamaz. Mat. Lapok 2 (1976), no. 1-2, 27-39. MR0438537 (55 \#11448)

[25] Y. L. Tong, The multivariate normal distribution, Springer Series in Statistics, SpringerVerlag, New York, 1990. MR1029032(91g:60021)

Department of Engineering, Mathematics and Physics, Faculty of Engineering, Cairo University, Cairo, Egypt 12613

E-mail address: h_fayed@eng.cu.edu.eg

Department of Computer Engineering, Faculty of Engineering, Cairo University, CAiro, Egypt 12613

E-mail address: amir@alumni.caltech.edu 